\title{
Sodium glucose transporter 2 (SGLT2) inhibition with empagliflozin improves cardiac diastolic function in a female rodent model of diabetes
}

\author{
Javad Habibi ${ }^{1,4+}$, Annayya R. Aroor ${ }^{1,4+}$, James R. Sowers ${ }^{1,3,4,5}$, Guanghong Jia ${ }^{1,4}$, Melvin R. Hayden , \\ Mona Garro ${ }^{1,4}$, Brady Barron 1,4, Eric Mayoux ${ }^{7}$, R. Scott Rector ${ }^{4,6}$, Adam Whaley-Connell 1,2,4 \\ and Vincent G. DeMarco $1,3,4^{*}$ (D)
}

\begin{abstract}
Obese and diabetic individuals are at increased risk for impairments in diastolic relaxation and heart failure with preserved ejection fraction. The impairments in diastolic relaxation are especially pronounced in obese and diabetic women and predict future cardiovascular disease (CVD) events in this population. Recent clinical data suggest sodium glucose transporter-2 (SGLT2) inhibition reduces CVD events in diabetic individuals, but the mechanisms of this CVD protection are unknown. To determine whether targeting SGLT2 improves diastolic relaxation, we utilized empagliflozin (EMPA) in female $\mathrm{db} / \mathrm{db}$ mice. Eleven week old female $\mathrm{db} / \mathrm{db}$ mice were fed normal mouse chow, with or without EMPA, for 5 weeks. Blood pressure (BP), HbA1c and fasting glucose were significantly increased in untreated $\mathrm{db} / \mathrm{db}$ mice $(\mathrm{DbC})(P<0.01)$. EMPA treatment $(\mathrm{DbE})$ improved glycemic indices $(P<0.05)$, but not $B P(P>0.05)$. At baseline, $\mathrm{DbC}$ and $\mathrm{DbE}$ had already established impaired diastolic relaxation as indicated by impaired septal wall motion (>tissue Doppler derived $E^{\prime} / A^{\prime}$ ratio) and increased left ventricular (LV) filling pressure ( $<E / E^{\prime}$ ratio). Although these abnormalities persisted throughout the study period in DbC, diastolic function improved with EMPA treatment. In DbC, myocardial fibrosis was accompanied by increased expression of profibrotic/prohypertrophic proteins, serum/ glucocorticoid regulated kinase 1 (SGK1) and the epithelial sodium channel (ENaC), and the development of these abnormalities were reduced with EMPA. DbC exhibited eccentric LV hypertrophy that was slightly improved by EMPA, indicated by a reduction in cardiomyocyte cross sectional area. In summary, EMPA improved glycemic indices along with diastolic relaxation, as well as SGK1/ENaC profibrosis signaling and associated interstitial fibrosis, all of which occurred in the absence of any changes in BP.
\end{abstract}

Keywords: Empagliflozin, SGLT2 inhibitor, Diastolic function

\section{Background}

The global epidemic of obesity is largely responsible for the increased incidence of type 2 diabetes mellitus and associated cardiovascular diseases (CVD). Affected

\footnotetext{
*Correspondence: demarcov@missouri.edu

† Javad Habibi and Annayya R. Aroor contributed equally to this work

${ }^{1}$ Department of Medicine, Division of Endocrinology, Diabetes

and Cardiovascular Center, University of Missouri, School of Medicine, Columbia, USA

Full list of author information is available at the end of the article
}

individuals are likely to have one or more CVD complications, such as hypertension and cardiac diastolic dysfunction; indeed, diabetes is often considered a CVD equivalent. In this regard, young (premenopausal) obese and diabetic women are particularly vulnerable to CVD $[1,2]$. Normally, young lean woman are at lower risk for development of CVD compared to men. However, this sex-related cardioprotection is lost in conditions of obesity or diabetes [3]. Diastolic dysfunction, which is defined by delayed diastolic relaxation [4], is associated 
with insulin resistance, cardiac fibrosis, hypertrophy, and inflammation [5, 6]. Diastolic heart failure, a CVD risk factor usually associated with aging, has dramatically increased in incidence in association with the increases in obesity and diabetes. Therefore, developing new strategies to improve both glycemia and CVD out comes in individuals afflicted with diabetes would be highly desirable, especially for women.

Diastolic dysfunction is typically associated with interstitial fibrosis and left ventricular (LV) hypertrophy that promote LV stiffness and impaired relaxation. In this regard, serum and glucocorticoid regulated kinase 1 (SGK1), which is highly expressed in the diabetic heart and is stimulated by excess circulating glucose, is emerging as a mediator of cardiac fibrosis/stiffening and impaired cardiac relaxation [7-10]. SGK1 stimulates a number of ion channels, including the epithelial sodium channel $(\mathrm{ENaC})$, as well as transporters, transcription factors and enzymes [11]. Indeed, we recently reported that fibrosis and stiffening of the aorta of overweight female mice fed a high fat, high sugar diet for 4 months was associated with increased aortic expression of SGK1 and $\mathrm{ENaC}$ [12].

In diabetes, hyperglycemia promotes a state of glucotoxicity, inflammation and oxidative stress which are associated with hypertension and end organ injury, including injury to the heart. In this regard, pharmacologic inhibitors of the renal sodium-glucose cotransporter 2 (SGLT2) are emerging as a novel group of drugs that lower blood glucose and HbA1c levels and improve whole body insulin sensitivity in animals and humans with diabetes, largely by blocking renal proximal tubular reabsorption of glucose which increases urinary glucose excretion (glycosuria) [13, 14]. The mild osmotic effects of SGLT2 inhibitor treatment can lead to modest reduction in blood pressure (BP), an effect, along with the improvement in glucose control and weight reduction that could reduce the risk of CVD. Indeed, a recent meta-analysis demonstrated favorable cardiovascular outcomes in diabetes patients treated with empagliflozin (EMPA) [15]. Administration of SGLT2 inhibitors to animals or humans with diabetes may also reduce adiposity, oxidative stress and expression of advanced glycation end products (AGE) and receptors for AGE (RAGE) [16]. Herein, we tested whether SGLT2 inhibitor therapy would attenuate the development of the earliest manifestation of diabetic heart disease, diastolic dysfunction, in part, by reducing blood pressure (BP), cardiac oxidative stress and pro-fibrotic factors. Diastolic dysfunction is especially pronounced in obese, insulin resistant and diabetic females [1, 2, 17-19]. Specifically, we hypothesized that the SGLT2i, EMPA would blunt the development/progression of diastolic dysfunction and the associated abnormalities in cardiac remodeling in insulin resistant female diabetic $\mathrm{db} / \mathrm{db}$ mice $\left(\right.$ Lepr $\left.^{\mathrm{db} / \mathrm{db}}\right)$. Previous reports demonstrate that female $\mathrm{db} / \mathrm{db}$ mice develop diastolic dysfunction, cardiac fibrosis and left ventricular hypertrophy (LVH) [20-22]. The $\mathrm{db} / \mathrm{db}$ model is clinically relevant in that hyperleptinemia and leptin resistance, obesity and associated heart disease are seen in the human obese population and leptin levels are elevated in conditions of chronic heart failure and chronic hypertension. The $\mathrm{db} / \mathrm{db}$ mouse exhibits a non-dipping BP pattern, diastolic dysfunction and cardiac remodeling; these CVD features of metabolic disease are also observed in obese and insulin resistant humans [20, 23-27]. Herein, we examined whether the anticipated improvement in diastolic function and cardiac remodeling with EMPA treatment would be associated with reductions in myocardial interstitial fibrosis, profibrotic signaling proteins, oxidative stress and improvements in myocardial mitochondrial ultrastructure.

\section{Methods \\ Animals}

All animal procedures were approved by the Harry $\mathrm{S}$ Truman Veterans Affairs Memorial Hospital Subcommittee for Animal Safety (SAS) and the University of Missouri IACUC. Eight week old female db/db (BKS.CgDock $\left.7^{\mathrm{m}}+/+\mathrm{Lepr}^{\mathrm{db}} / \mathrm{J}\right)$ and wild-type control (C57BLKS/J) mice were purchased from Jackson Labs and were housed under standard laboratory conditions where room temperature was $21-22{ }^{\circ} \mathrm{C}$ and light and dark cycles were $12 \mathrm{~h}$ each. Three different cohorts of mice were used for these studies. Each cohort consisted of three groups of mice including lean untreated controls $(\mathrm{CkC})$, untreated $\mathrm{db} / \mathrm{db}(\mathrm{DbC})$ and $\mathrm{db} / \mathrm{db}$ treated with EMPA (DbE) for 5 weeks. In total there were $17 \mathrm{CkC}, 19 \mathrm{DbC}$ and $19 \mathrm{DbE}$. The first and second cohorts consisted of 5-6 mice per group and subsets of these mice were used for cardiac function, urine and plasma biochemistry, histological (light and electron microscopy) and immunological studies. The third cohort consisted of 6-7 mice per group that were used primarily for ambulatory BP monitoring. Two DbC and two DbE were removed from Cohort3 following acute complications from telemetry implant surgery. The radiotransmitter in another $\mathrm{DbC}$ failed in the middle of the study and one $\mathrm{CkC}$ with a radiotransmitter succumbed late in the study. Of the 55 mice used, six mice, all from Cohort3, did not complete the study. The treatment period began when mice were 11 weeks of age and ended 5 weeks later when mice were 16 weeks of age. Previous reports indicate that cardiac dysfunction and remodeling in female $\mathrm{db} / \mathrm{db}$ mice begin to develop and progress during the time frame of our experiment [20-22]. 


\section{EMPA administration}

EMPA is a potent and competitive inhibitor of SGLT2 with the highest selectivity profile of recently tested SGLT2i [28]. We mixed EMPA in normal mouse chow (Purina Diet 5008) at a concentration $\left(60 \mathrm{mg} \mathrm{kg}^{-1}\right.$ of diet) calculated to deliver $10 \mathrm{mg} \mathrm{kg}^{-1}$ day $^{-1}$ based on food intake [13]. This dose of EMPA significantly improves HbA1c, 2 h glucose concentration during oral glucose tolerance test (OGTT) and insulin sensitivity by insulin euglycemic-hyperinsulinemic clamp and tends to lower circulating lipids in 17 week old female $\mathrm{db} / \mathrm{db}$ mice [13].

\section{Blood and tissue biochemistry}

Mice were fasted for $4 \mathrm{~h}$ in the morning (5-9 a.m.) prior to collection of a small blood sample from the tail vein. Blood was analyzed for glucose using an Alpha Trak II glucometer and for HbA1c using a DCA Vantage Analyzer (Seimens, Malvern, PA). Samples were drawn immediately prior to the start of the treatment period, midway and at the end of the study. At the end of the study mice were anesthetized with $3 \%$ isoflurane and a terminal blood sample was drawn immediately from the left ventricle. Blood was centrifuged and plasma was stored at $-80{ }^{\circ} \mathrm{C}$. Plasma was analyzed for insulin concentration using an ELISA kit specific for mouse insulin using a previously established protocol [29], as well as cholesterol, triglycerides, alanine aminotransferase and uric acid using commercially-available automated assays (Beckman-Coulter, Inc., Brey, CA). Liver samples were analyzed for triglyceride content using a previously established protocol [30]. Plasma electrolytes $\left(\mathrm{Na}^{+}, \mathrm{K}^{+}\right.$ and $\mathrm{Cl}^{-}$) were measured on the same clinical chemistry platform using ion-specific electrodes.

\section{Urine analyses}

Immediately prior to the start of treatment, in the middle of the treatment period and within $48 \mathrm{~h}$ of the end of treatment, mice were placed in metabolic chambers for $24 \mathrm{~h}$ urine collection and subsequent determination of concentrations of electrolytes and glucose. Urine was stored at $-80{ }^{\circ} \mathrm{C}$ except for a $60 \mu \mathrm{l}$ aliquot that was refrigerated overnight and analyzed for microalbumin and creatine, as well as the ratio of micro-albumin to creatine as a standardized measure of microalbuminuria, using a DCA Vantage analyzer.

\section{Body composition}

Prior to both the start of treatment and the end of the study,whole body composition was analyzed by nuclear magnetic resonance spectroscopy (Echo MRI, Houston, TX).

\section{BP monitoring}

Ambulatory BP and BP dipping status during the light and dark cycles were monitored weekly by radiotelemetry as previously described [31, 32].

\section{Echocardiography}

Transthoracic echocardiography (TTE) was performed on isoflurane $(1.75 \%$ in an oxygen stream) anesthetized mice as previously described [31, 33] using a GE Vividi ultrasound system. Initially, we performed TEE immediately prior to the beginning of the treatment period and again at the end of the treatment period.

\section{Quantification of interstitial fibrosis}

One mm thick coronal slices of the heart just below the level of the papillary muscle were fixed in paraformaldehyde, embedded in paraffin, sectioned at $5 \mu$ and stained for collagens using picro-Sirius-red, as previously described [34]. Images were taken with $5 \times$ and $40 \times$ objective lenses. A region of interest rectangle of known area was randomly placed in three areas and images were captured using a Nikon50i microscope, a $40 \times$ objective and cool snapcf camera and software. Each image was auto-leveled with Photoshop and the intensity of pink color was normalized to area and quantified using MetaVue software. For each animal an average estimate of fibrosis was calculated from the three determinations of collagen staining.

\section{Heart immunohistochemistry and immunoblotting}

To evaluate the level of oxidative/nitrosative damage to myocardial proteins samples of the left ventricle (LV) free wall were fixed, embedded in paraplast, sectioned and assessed for 3-nitrotyrosine (3-NTY) residue using an immunofluorescence technique we described previously $[34,35]$. LV tissue sections were also evaluated by immunofluorescence for wheat germ agglutinin (WGA, 1:50, \#W11261, Invitrogen), AGE (1:100, \#23722, Abcam), RAGE (1:50, \#AF1179, R\&D), SGK1 (1:100, \#32374, Abcam) and ENaC (1:200, \#77385, Abcam) expression. Average grey scale intensity was quantified within fixed region of interest rectangles as previously described [35].

Preparation of LV homogenates, electrophoresis and immunoblotting were described previously [34]. The following antibodies were used: phospho-Akt Ser308 (1:1000; \#4056, Cell Signaling Technology, Inc or CST), phospho$\operatorname{Akt}^{\operatorname{Ser} 473}$ (1:1000; \#9271, CST), Akt (1:1000; \#9272, CST), eNaC (1:1000; \#77385, Abcam), RAGE (1:1000; \#AF1179, R\&D), Phospho-ERK T202/204 (1:1000; \#9106, CST), ERK (1:1000; \#4695, CST) and pan-actin (1:1000; \#4968, CST). 


\section{Ultrastructure analysis using transmission electron microscopy (TEM)}

Briefly, samples of the LV free wall were cut into $2 \mathrm{~mm}$ squares and placed immediately in primary TEM fixative as previously described. Specimens were then placed in resin and polymerized at $60{ }^{\circ} \mathrm{C}$ for $24 \mathrm{~h}$. Ultrathin sections $(85 \mathrm{~nm})$ were stained with $5 \%$ uranyl acetate and Sato's Triple lead stain. A JOEL 1400-EX TEM (Joel, Tokyo, Japan) was used to view three fields randomly chosen per mouse to obtain three $2000 \times$ images per LV [36].

\section{Statistical analysis}

Results are reported as the mean \pm SE. Differences in outcomes were determined using one-way ANOVA and Bonferroni post hoc tests for paired comparisons and were considered significant when $\mathrm{P}<0.05$. For comparisons regarding plasma insulin concentration at the end of the study, a Kruskal-Wallis ANOVA was used in place of standard ANOVA. All statistical analyses were performed using Sigma Plot (version 12) software (Systat Software, Point Richmond, CA).

\section{Results}

\section{Baseline parameters}

Compared to $\mathrm{CkC}$ mice, body weights of $\mathrm{DbC}$ and $\mathrm{DbE}$ mice were both 2.74-fold greater and this was due largely to the more than 12-fold increases in whole body fat mass, and to a lesser extent to 20 and $24 \%$ increases in whole body lean mass, in $\mathrm{DbC}$ and $\mathrm{DbE}$, respectively (Additional file 1: Figure S1A; Table 1; $\mathrm{P}<0.001$ ). The slightly greater gain in lean mass in $\mathrm{DbE}$ compared to $\mathrm{DbC}$ did not reach statistical significance (Additional file 1: Figure S1B-E). The percentage of whole body water weight of $\mathrm{DbC}$ and $\mathrm{DbE}$ was less than half that of $\mathrm{CkC}$ and did not differ between the treated and untreated $\mathrm{db} /$ $\mathrm{db}$ groups.

\section{Metabolic parameters}

Plasma cholesterol, triglycerides and alanine aminotransferase (ALT) were similarly elevated in both $\mathrm{DbC}$ and DbE indicating metabolic dyslipidemia and liver impairment in $\mathrm{DbC}$ and $\mathrm{DbE}$ (Table 1). Compared to $\mathrm{CkC}$, liver triglyceride content was elevated in $\mathrm{DbC}$ and this was not altered by EMPA (Table 1). Plasma electrolytes did not differ among groups (not shown).

Baseline fasting glucose and $\mathrm{HbA} 1 \mathrm{c}$ of $\mathrm{CkC}$ mice were $155 \pm 15 \mathrm{mg} \mathrm{dl}^{-1}$ and $3.7 \pm 0.1 \%$, respectively and these parameters did not differ at the end of the study (Fig. 1a, b). At both measuring times, i.e., before treatment began and at the end of the treatment period, $\mathrm{DbC}$ and DbE mice had elevated fasting glucose and HbA1c consistent with diabetes, compared to $\mathrm{CkC}$. By the end of
Table 1 Baseline parameters, including body and liver weights, as well as post-treatment plasma metabolic markers of lean control (CkC), untreated $\mathrm{db} / \mathrm{db}(\mathrm{DbC})$ and $\mathrm{db} / \mathrm{db}$ mice treated with EMPA (DbE)

\begin{tabular}{|c|c|c|c|c|}
\hline Parameter & $\begin{array}{l}\text { ANOVA } \\
\text { P value }\end{array}$ & $\begin{array}{l}\mathrm{CkC} \\
(11)\end{array}$ & $\begin{array}{l}\mathrm{DbC} \\
(12)\end{array}$ & $\begin{array}{l}\mathrm{DbE} \\
(13)\end{array}$ \\
\hline \multicolumn{5}{|l|}{ Body weight } \\
\hline $\begin{array}{l}\text { Pre-treatment } \\
\text { body weight (g) }\end{array}$ & 0.001 & $18.9 \pm 0.2$ & $46.1^{*} \pm 0.7$ & $45.4^{\S} \pm 0.7$ \\
\hline $\begin{array}{l}\text { Post-treatment } \\
\text { body weight (g) }\end{array}$ & 0.001 & $19.2 \pm 0.3$ & $53.6^{*} \pm 1.0$ & $53.5^{\S} \pm 0.7$ \\
\hline Delta (g) & 0.001 & $0.17 \pm 0.29$ & $7.50^{*} \pm 0.76$ & $8.32^{\S} \pm 0.50$ \\
\hline $\begin{array}{l}\% \text { Increase in } \\
\text { body weight }\end{array}$ & 0.001 & $0.7 \pm 1.6$ & $13.8^{*} \pm 1.3$ & $15.5^{\S} \pm 0.9$ \\
\hline \multicolumn{5}{|l|}{ Hepatic } \\
\hline Liver weight (mg) & 0.001 & $835 \pm 37$ & $2460^{*, \dagger} \pm 92$ & $2031^{\S} \pm 72$ \\
\hline $\begin{array}{l}\text { Triglycerides } \\
\qquad\left(\mathrm{nmol} \mathrm{g}^{-1}\right)\end{array}$ & 0.001 & $15 \pm 3$ & $43^{*} \pm 5$ & $37^{\S} \pm 4$ \\
\hline \multicolumn{5}{|l|}{ Plasma } \\
\hline $\begin{array}{r}\text { Cholesterol } \\
\left(\mathrm{mg} \mathrm{dl}^{-1}\right)\end{array}$ & 0.001 & $76 \pm 5$ & $145^{*} \pm 3$ & $148^{\S} \pm 6$ \\
\hline $\begin{array}{l}\text { Triglycerides } \\
\qquad\left(\mathrm{mg} \mathrm{dl}^{-1}\right)\end{array}$ & 0.001 & $126 \pm 9$ & $310^{*} \pm 18$ & $301^{\S} \pm 20$ \\
\hline $\begin{array}{l}\text { Alanine } \\
\text { aminotransferase } \\
\left(\left.\cup\right|^{-1}\right)\end{array}$ & 0.001 & $27 \pm 2$ & $78^{*} \pm 5$ & $69^{\S} \pm 8$ \\
\hline
\end{tabular}

Values are mean $\pm \mathrm{SE}$. Post-hoc comparisons; $\mathrm{P}<0.05$ for ${ }^{*} \mathrm{CkC}$ vs $\mathrm{DbC} ;{ }^{\dagger} \mathrm{DbCvs}$ $\mathrm{DbE}$; and ${ }^{\S} \mathrm{CkC}$ vs DbE. Sample sizes are noted in parentheses

the 5 week study period, the fasting glucose and HbA1c of $\mathrm{DbC}$ were both elevated compared to pre-treatment levels. Compared to pre-treatment values, DbE exhibited lower fasting glucose and HbA1c was unchanged. Moreover, both glycemic parameters in DbE were significantly reduced by the end of the treatment period compared to $\mathrm{DbC}$. These data indicate that progressing hyperglycemia was abrogated by EMPA. In this study, 16 week old $\mathrm{DbC}$ and $\mathrm{DbE}$ had higher plasma insulin concentrations compared to $\mathrm{CkC}(\mathrm{P}<0.05$ for each) (Fig. 1c). The higher insulin levels in DbE were associated with an increase in pancreas weight compared to $\mathrm{CkC}$ and $\mathrm{DbC}$ (Fig. 1d). To evaluate urine glucose excretion (UGE) at the end of the study, we normalized urine glucose concentration to fasting glucose concentration and observed that the UGE of DbC and DbE mice were 54- and 111-fold higher than that of $\mathrm{CkC}$ (Fig. 1e; $\mathrm{P}<0.001)$.

\section{BP and BP dipping status is unaffected by SGLT2i}

At the end of the treatment period daytime ambulatory systolic BP (SBP) and diastolic BP (DBP) were elevated in both $\mathrm{DbC}$ and $\mathrm{DbE}$, compared to $\mathrm{CkC}$ (Fig. 2a). SBP and DBP were also elevated during the dark cycle although the trends were not significant over as many time points 

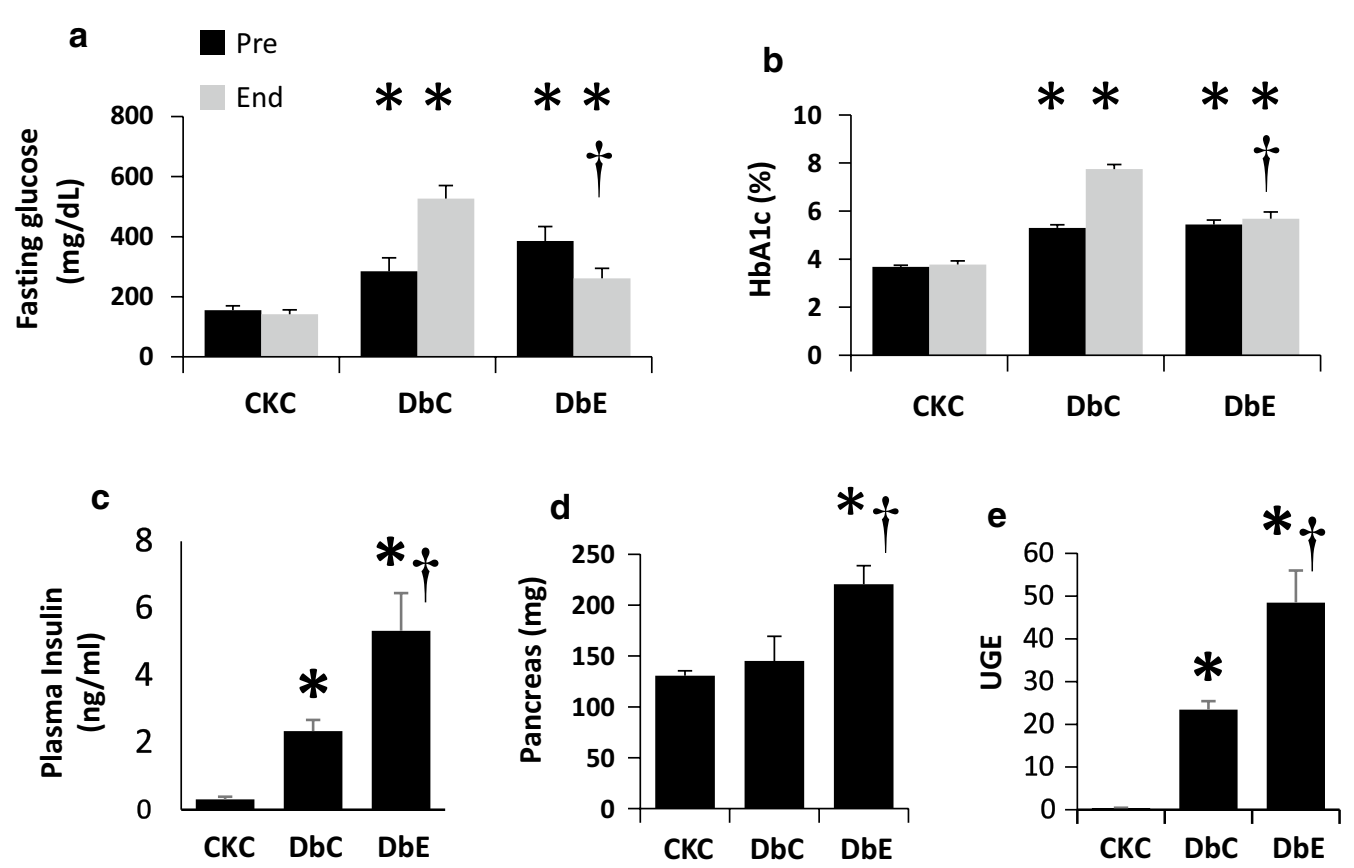

Fig. 1 Empagliflozin improves dysglycemia in db/db mice. Db/db mice have elevated fasting glucose and HbA1c levels prior to the start of treatment. During the 5 week study period, dysglycemia was sustained in untreated db/db mice (DbC); however both a fasting glucose and $\mathbf{b} \mathrm{HbA1c}$ were reduced in $\mathrm{db} / \mathrm{db}$ treated with empagliflozin (DbE) by the end of the study. At the end of the study, DbE had increased c serum insulin concentrations and d pancreas mass e compared to CKC and DbC. e Compared to CkC, urine glucose excretion (UGE) was elevated in both $\mathrm{db} / \mathrm{db}$ groups of mice, but UGE was twofold higher in DbE compared to DbC. ${ }^{*} \mathrm{P}<0.05$ compared to CkC at the same time point; ${ }^{\dagger} \mathrm{P}<0.05$ compared to $\mathrm{DbC}$ at the same time point

as occurred during the light cycle (Fig. 2b). The percentage decrease in SBP between the light and dark cycles, also known as BP dipping status, ranged between 7.5 and $9.8 \%$ in $\mathrm{CkC}$ over study period (Fig. 2c). It should be noted that normal BP dipping is defined as a decrease in $\mathrm{BP}$ of at least $10 \%$ between the light and dark cycles. BP dipping status tended to be similarly impaired in $\mathrm{DbC}$ and DbE between 12 and 15 weeks of age, although all three groups of mice had similar dipping status at 16 weeks of age.

\section{Cardiac function is improved with SGLT2i Pre-treatment}

Compared to $\mathrm{CkC}, \mathrm{DbC}$ and $\mathrm{DbE}$ exhibited impairments in diastolic relaxation (Table 2), including reductions in early septal annular velocity $\left(E^{\prime}\right)$ and the ratio of early $\left(\mathrm{E}^{\prime}\right)$ to late $\left(\mathrm{A}^{\prime}\right)$ septal annular velocity. This occurred in association with an increase in an index of LV filling pressure, the $E / E^{\prime}$ ratio, specifically, the ratio of peak early mitral inflow velocity to peak early septal annular velocity. Left atrial (LA) diameter relative to the diameter of the aorta (Ao) increases in response to an increase in LV filling pressure. The observed increase in the ratio of LA to Ao diameters is consistent with increased LV filling pressure (E/E' ratio) in both groups of the $\mathrm{db} / \mathrm{db}$ mice. In contrast, we did not observe differences among groups in early (E) or late (A) mitral inflow velocity or in the E/A ratio, the latter being an often reported marker of diastolic dysfunction. There were no significant differences in the systolic function parameters, ejection fraction (EF) and fractional shortening (FS) among the three groups. As expected in the setting of obesity, cardiac output (CO) and stroke volume (SV) were elevated in the $\mathrm{DbC}$ and $\mathrm{DbE}$ groups compared to the lean $\mathrm{CkC}$ mice. Measures of LV wall thickness tended to be slightly greater in $\mathrm{DbC}$ and DbE and LV lumen diameters were similar among groups. Relative wall thickness did not vary significantly among the three groups of mice.

\section{End of treatment}

The diastolic impairments observed in the untreated $\mathrm{DbC}$ group at the earlier time point were, in most cases, maintained until the end of the study (Table 2; Fig. 3). On the other hand, early septal annular velocity $\left(E^{\prime}\right)$ tended to increase and late septal annular velocity $\left(\mathrm{A}^{\prime}\right)$ tended to decrease in DbE relative to measurements taken 5 weeks earlier. These modest improvements in $\mathrm{E}^{\prime}$ and $\mathrm{A}^{\prime}$ contributed to the significant increase in the $E^{\prime} / A^{\prime}$ ratio in 

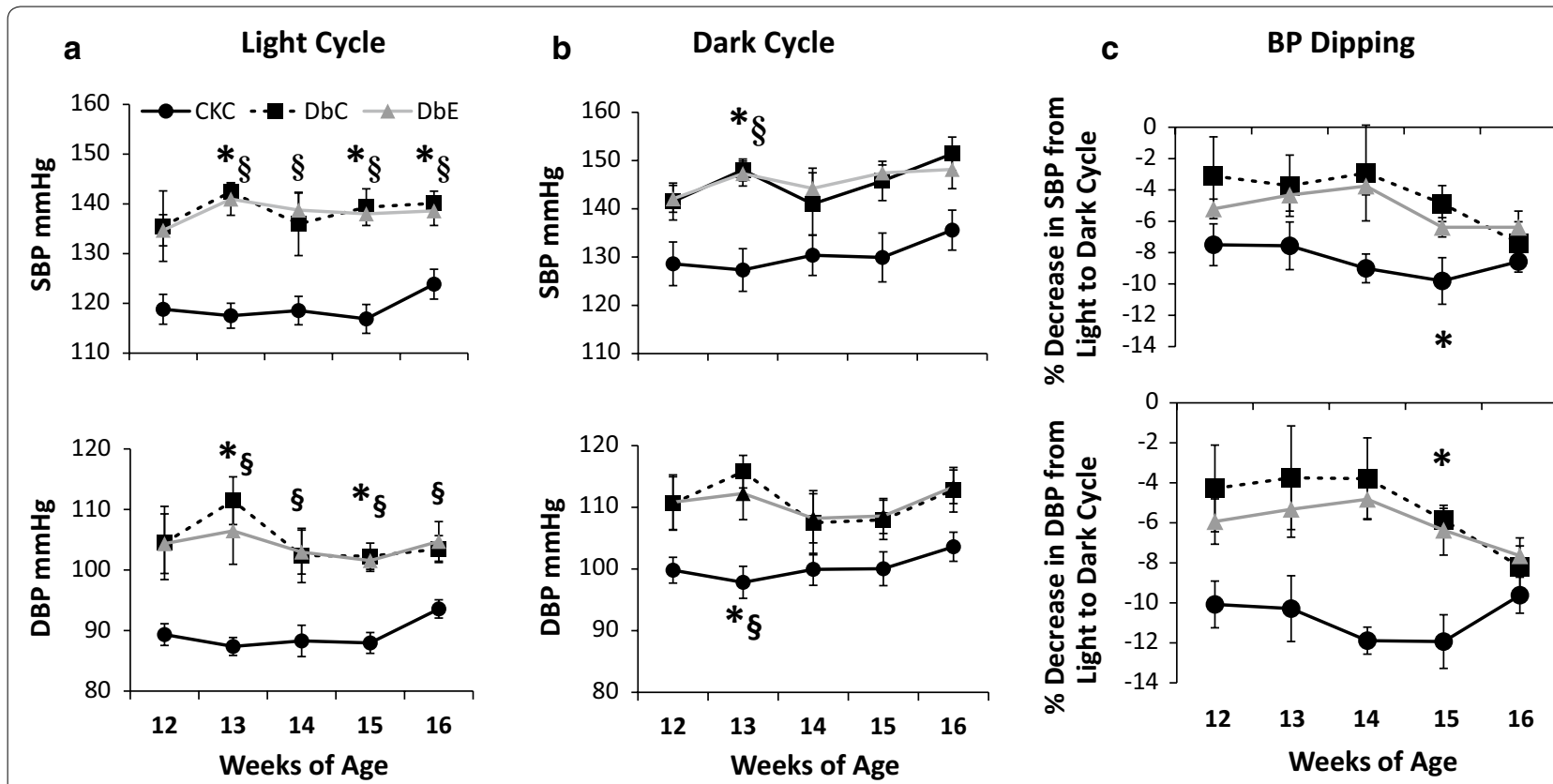

Fig. 2 Mean ambulatory systolic and diastolic blood pressures were recorded at weekly intervals during the light $\mathbf{a}$ and dark $\mathbf{b}$ cycles. Compared to $\mathrm{CKC}$, both $\mathrm{DbC}$ and $\mathrm{DbE}$ exhibited a mild elevation in blood pressure $(\mathrm{P}<0.05)$, especially during the light cycle and tended to have impaired blood pressure dipping $(\mathbf{c})$, neither of which was affected by empagliflozin treatment. ${ }^{*} \mathrm{P}<0.05 \mathrm{DbC}$ vs $\mathrm{CkC}$ and ${ }^{\S} \mathrm{P}<0.05 \mathrm{DbE}$ vs $\mathrm{CkC}$

DbE (Fig. 3a). Moreover, LV filling pressure (E/E') was significantly lower in $\mathrm{DbE}$ compared to $\mathrm{DbC}$, yet this was not accompanied by a decrease in the LA/Ao ratio (Fig. 3b). This suggests that reversal of LA remodeling may not occur contemporaneously with therapeutic reduction in filling pressure [37]. In contrast, we did not observe differences among groups in early (E) or late (A) mitral inflow velocity or in the E/A ratio, nor were there differences in indices $\mathrm{EF}$ or FS. Relative to $\mathrm{CkC}, \mathrm{CO}$ and $\mathrm{SV}$ were still significantly elevated in the $\mathrm{DbC}$, but not $\mathrm{DbE}$ mice.

\section{LV hypertrophy is ameliorated by SGLT $2 \mathrm{i}$}

We observed increases in LV mass, determined by $\mathrm{M}$-mode ultrasound, in $\mathrm{DbC}$ and $\mathrm{DbE}$ compared to $\mathrm{CkC}$ (Table 2). On the other hand, echocardiographic measures of LV wall thickness at end diastole (LVAWTd and LVPWTd) and lumen diameters at end diastole and end systole (LVIDd and LVIDs) were similar among the three groups of mice. Left ventricular cardiomyocyte cross sectional area, a correlate of cardiomyocyte hypertrophy, was elevated in both DbC compared to CkC (Fig. 4a). Interestingly, cardiomyocyte cross sectional area was significantly reduced in $\mathrm{DbE}$ compared to $\mathrm{DbC}$, although it did not reduce to that of $\mathrm{CkC}$. The increases in $\mathrm{CO}, \mathrm{LV}$ filling pressure, cardiomyocyte size and LV mass, in the absence of an increase in LV wall thickness, comprise a suite of traits suggestive of eccentric hypertrophy. It should be noted that the most prevalent LV remodeling abnormality in obese hypertensive individuals is eccentric hypertrophy [38]. The lower CO and LV filling pressure observed in $\mathrm{DbE}$ are consistent with reduced cardiomyocyte cross sectional area and suggest that the progression of the hypertrophic phenotype is mildly ameliorated with EMPA treatment.

\section{Myocardial fibrosis is improved with SGLT2i}

At the end of treatment, the myocardium of DbC exhibited $50 \%$ greater picrosirius red staining than that of $\mathrm{CkC}$, indicative of increased collagen I and III deposition in the interstitium (Fig. 4b). Myocardial picrosirius red staining in $\mathrm{DbE}$ was significantly reduced compared to $\mathrm{DbC}$ and was not different from $\mathrm{CkC}$. Immunostaining for the more tensile type 1 collagen revealed a similar pattern of increasing collagen 1 in $\mathrm{DbC}$ compared to both $\mathrm{CkC}$ and $\mathrm{DbE}(14.8 \pm 3.3$ vs $11.1 \pm 0.9$ and $10.2 \pm 0.3$, respectively; $\mathrm{P}>0.05$ ), however the differences were not statistically different.

\section{Myocardial oxidative/nitrosative stress, AGE and RAGE}

Oxidant stress contributes to AGE/RAGE activation in diabetes. The myocardium of $\mathrm{DbC}$ exhibited 2.6-fold greater 3-NTY immunostaining compared to $\mathrm{CkC}$, indicative of increased accumulation of nitro tyrosinolated protein damage in the interstitium (Fig. 4c). Compared to DbC, staining of 3-NTY tended to be slightly lower in $\mathrm{DbE}$, compared to $\mathrm{DbC}$, but was not significant 
Table 2 Summary (mean \pm SE) of cardiac pulse wave, tissue Doppler and M-mode imaging parameters measured before (pre) and after treatment (post) with the SGLT-2 inhibitor

\begin{tabular}{|c|c|c|c|c|c|c|c|c|c|}
\hline \multirow[t]{2}{*}{ Parameter } & \multicolumn{5}{|c|}{ Pre-treatment } & \multicolumn{4}{|l|}{ Post-treatment } \\
\hline & \multicolumn{2}{|l|}{ CkC (9) } & $\mathrm{DbC}(6)$ & $\mathrm{DbE}(6)$ & $P$ value & CkC (9) & $\mathrm{DbC}(6)$ & $\mathrm{DbE}(6)$ & $P$ value \\
\hline \multicolumn{10}{|c|}{ Diastolic function } \\
\hline $\mathrm{E}, \mathrm{ms}^{-1}$ & $665 \pm 28$ & \multicolumn{2}{|c|}{$641 \pm 40$} & $696 \pm 50$ & ND & $632 \pm 25$ & $680 \pm 29$ & $647 \pm 57$ & ND \\
\hline$A, \mathrm{~ms}^{-1}$ & $455 \pm 34$ & \multicolumn{2}{|c|}{$508 \pm 19$} & $463 \pm 34$ & ND & $417 \pm 24$ & $510 \pm 31$ & $470 \pm 45$ & ND \\
\hline$E / A$ & $1.52 \pm 0.12$ & \multicolumn{2}{|c|}{$1.26 \pm 0.05$} & $1.53 \pm 0.12$ & ND & $1.5 \pm 0.08$ & $1.35 \pm 0.09$ & $1.39 \pm 0.06$ & ND \\
\hline $\mathrm{Dt}, \mathrm{ms}$ & $29.4 \pm 3.0$ & \multicolumn{2}{|c|}{$32.7 \pm 3.9$} & $27.8 \pm 1.8$ & ND & $24.9 \pm 1.8$ & $31.1 \pm 3.3$ & $26.3 \pm 1.8$ & ND \\
\hline $\mathrm{E}^{\prime}, \mathrm{ms}^{-1}$ & $27.0 \pm 1.8$ & & $\pm 1.6^{*}$ & $15.9 \pm 2.2$ & $<0.001$ & $26.9 \pm 1.4$ & $15.5 \pm 1.7^{*}$ & $20.4 \pm 1.2$ & $<0.001$ \\
\hline $\mathrm{A}^{\prime}, \mathrm{ms}^{-1}$ & $21.5 \pm 2.5$ & & \pm 0.8 & $18.0 \pm 4.1$ & ND & $19.0 \pm 1.7$ & $18.3 \pm 2.7$ & $11.9 \pm 0.9^{\S}$ & 0.036 \\
\hline$E^{\prime} / A^{\prime}$ & $1.31 \pm 0.09$ & & $\pm 0.08^{*}$ & $0.93 \pm 0.07^{\S}$ & 0.002 & $1.47 \pm 0.11$ & $0.89 \pm 0.08^{*, \dagger}$ & $1.76 \pm 0.17$ & $<0.001$ \\
\hline$E / E^{\prime}$ & $25.3 \pm 1.7$ & & $\pm 5.6^{*}$ & $47 \pm 2.5^{\S}$ & $<0.001$ & $24 \pm 1.6$ & $46 \pm 4.4^{*, \dagger}$ & $29 \pm 1.8$ & $<0.001$ \\
\hline$\left(E / E^{\prime} / I D d\right)$ & $8.7 \pm 0.4$ & & \pm 1.8 & $12.4 \pm 0.6$ & ND & $7.8 \pm 0.5$ & $12.3 \pm 1.3^{*, t}$ & $7.8 \pm 0.9$ & 0.009 \\
\hline IVRT, ms & $20.9 \pm 1.8$ & & \pm 0.8 & $18.0 \pm 1.0$ & ND & $19.0 \pm 2.3$ & $16.0 \pm 0.4$ & $15.8 \pm 0.4$ & ND \\
\hline $\mathrm{LA}, \mathrm{mm}$ & $1.55 \pm 0.10$ & & $\pm 0.13^{*}$ & $2.25 \pm 0.10^{\S}$ & $<0.001$ & $1.40 \pm 0.06$ & $1.97 \pm 0.03^{*}$ & $2.04 \pm 0.1^{\S}$ & $<0.001$ \\
\hline $\mathrm{Ao}, \mathrm{mm}$ & $1.21 \pm 0.06$ & & \pm 0.02 & $1.42 \pm 0.05$ & 0.077 & $1.26 \pm 0.06$ & $1.29 \pm 0.02$ & $1.27 \pm 0.05$ & ND \\
\hline LA/Ao & $1.29 \pm 0.07$ & & $\pm 0.09^{*}$ & $1.60 \pm 0.11^{\mathrm{a}}$ & 0.009 & $1.14 \pm 0.08$ & $1.54 \pm 0.11^{*}$ & $1.61 \pm 0.1^{\S}$ & 0.003 \\
\hline Parameter & Pre & atme & & & & Post-treatm & ent & & \\
\hline & $\mathrm{CkC}$ & & $\mathrm{DbC}(6)$ & $\mathrm{DbE}(6)$ & $P$ value & CkC (5) & $\mathrm{DbC}(6)$ & $\mathrm{DbE}(6)$ & $P$ value \\
\hline Systolic function & & & & & & & & & \\
\hline$E F, \%$ & & & $76 \pm 1$ & $71 \pm 2$ & ND & $74 \pm 2$ & $74 \pm 3$ & $76 \pm 2$ & ND \\
\hline$F S, \%$ & & & $44 \pm 1$ & $39 \pm 2$ & ND & $42 \pm 2$ & $43 \pm 3$ & $45 \pm 2$ & ND \\
\hline $\mathrm{CO}, \mathrm{ml} \mathrm{\textrm {min } ^ { - 1 }}$ & & & $41 \pm 5^{*}$ & $41 \pm 4^{\S}$ & 0.001 & $29 \pm 3$ & $49 \pm 5^{*}$ & $39 \pm 5$ & 0.02 \\
\hline$S V, \mu l$ & & & $101 \pm 11^{*}$ & $95 \pm 5^{\S}$ & 0.016 & $63 \pm 7$ & $108 \pm 9^{*}$ & $87 \pm 10$ & 0.01 \\
\hline Left ventricle wa & and lumen & asures & & & & & & & \\
\hline LVAWTd, mm & 0.70 & 0.07 & $0.91 \pm 0.05^{*}$ & $0.85 \pm 0.04$ & 0.052 & $0.81 \pm 0.05$ & $0.82 \pm 0.11$ & $0.84 \pm 0.05$ & ND \\
\hline LVIDd, mm & 3.40 & 0.14 & $3.52 \pm 0.11$ & $3.68 \pm 0.14$ & ND & $3.50 \pm 0.05$ & $3.79 \pm 0.17$ & $3.86 \pm 0.19$ & ND \\
\hline LVPWTd, mm & 0.69 & 0.04 & $0.83 \pm 0.04^{*}$ & $0.78 \pm 0.04$ & 0.026 & $0.75 \pm 0.02$ & $0.92 \pm 0.09$ & $0.83 \pm 0.05$ & ND \\
\hline LVIDs, mm & 2.00 & 0.24 & $1.96 \pm 0.08$ & $2.23 \pm 0.13$ & ND & $2.13 \pm 0.12$ & $2.28 \pm 0.17$ & $2.27 \pm 0.11$ & ND \\
\hline RWT & 0.41 & 0.03 & $0.49 \pm 0.03$ & $0.45 \pm 0.03$ & ND & $0.45 \pm 0.02$ & $0.48 \pm 0.08$ & $0.43 \pm 0.03$ & ND \\
\hline LVM, mg & & & $86 \pm 4^{*}$ & $81 \pm 3^{\S}$ & 0.001 & $76 \pm 3$ & $97 \pm 7$ & $98 \pm 9$ & 0.073 \\
\hline $\mathrm{LVM} / \mathrm{TL}$, mg m & & & & & & $4.30 \pm 0.17$ & $5.56 \pm 0.36$ & $5.71 \pm 0.52$ & 0.057 \\
\hline
\end{tabular}

Evelocity of early mitral flow, $A$ velocity of late mitral flow, $D t$ deceleration time of early mitral inflow, $E^{\prime}$ early peak velocity of septal annulus, $A^{\prime}$ late peak velocity of septal annulus, E/E' index of LA filling pressure, (E/E)/LVIDd index of diastolic stiffness, IVRT isovolumic relaxation time, $L A$ left atrium diameter, Ao aorta diameter, EF ejection fraction, FS fractional shortening, CO cardiac output, SV stroke volume, LVAWTd anterior wall thickness at end diastole, LVIDd LV inner diameter at end diastole, LVPWTd LV wall thickness at end diastole, LVIDs LV inner diameter at end systole, RWT relative wall thickness, LVM LV mass, TL tibia length (only available posttreatment), $N D$ no differences

Numbers in parentheses are sample sizes. Within time point post hoc comparisons: ${ }^{*} \mathrm{P}<0.05$ for $\mathrm{CkC}$ vs DbC; ${ }^{\dagger} \mathrm{DbC}$ vs DbE; ${ }^{\S} \mathrm{CkC}$ vs $\mathrm{DbE} ;{ }^{\mathrm{a}} \mathrm{P}<0.051 \mathrm{CkC}$ vs $\mathrm{DbE}$

$(\mathrm{P}>0.05)$. In $\mathrm{DbC}$, there were concomitant increases of 55 and $66 \%$, respectively, in myocardial expression of $\mathrm{AGE}$ and RAGE, compared to $\mathrm{CkC}$ (Fig. 5a-c). In the myocardium of $\mathrm{CkC}$, the basal level of AGE staining indicates low level expression in the parenchyma with more prominent staining in the vascular wall. In the $\mathrm{DbC}$, there are increases in AGE staining in both the parenchyma and vascular wall. EMPA did not reduce the accumulations of AGE or RAGE in the DbE heart. Although oxidant damage likely contributes to fibrosis and diastolic dysfunction, we and others have observed interventional improvement in diastolic dysfunction in the absence of significant reductions in myocardial oxidative/nitrosative stress [31, 39].

\section{SGK1 and ENaC expression are reduced with SGLT2i}

SGK1 is highly expressed in the myocardium, especially in the setting of obesity and diabetes and is emerging as a contributor to cardiac fibrosis/stiffening, hypertrophy and impaired cardiac relaxation [7-9]. Additionally, 

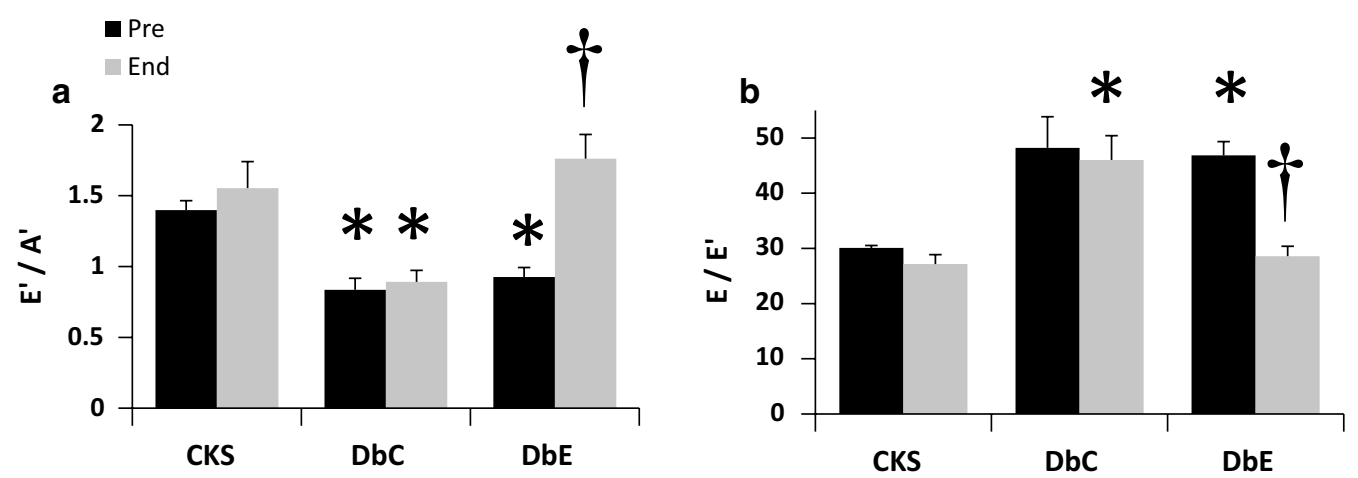

Fig. 3 Echocardiographic assessment of diastolic function. Cardiac function was evaluated in 11 week old mice prior to treatment (Pre) and again at 15 weeks of age at the end of treatment. Bar graphs show significant improvements in diastolic parameters in DbE compared to DbC including the $\mathbf{a}$ Tissue Doppler derived $\mathrm{E}^{\prime} / \mathrm{A}^{\prime}$ ratio indicating improved septal wall motion and $\mathbf{b} \mathrm{E} / \mathrm{E}^{\prime}$ ratio indicating improved $L V$ filling pressure. ${ }^{*} \mathrm{P}<0.05$ compared to CKC at the same time point; ${ }^{\dagger} \mathrm{P}<0.05$ compared to $\mathrm{DbC}$ at the same time point

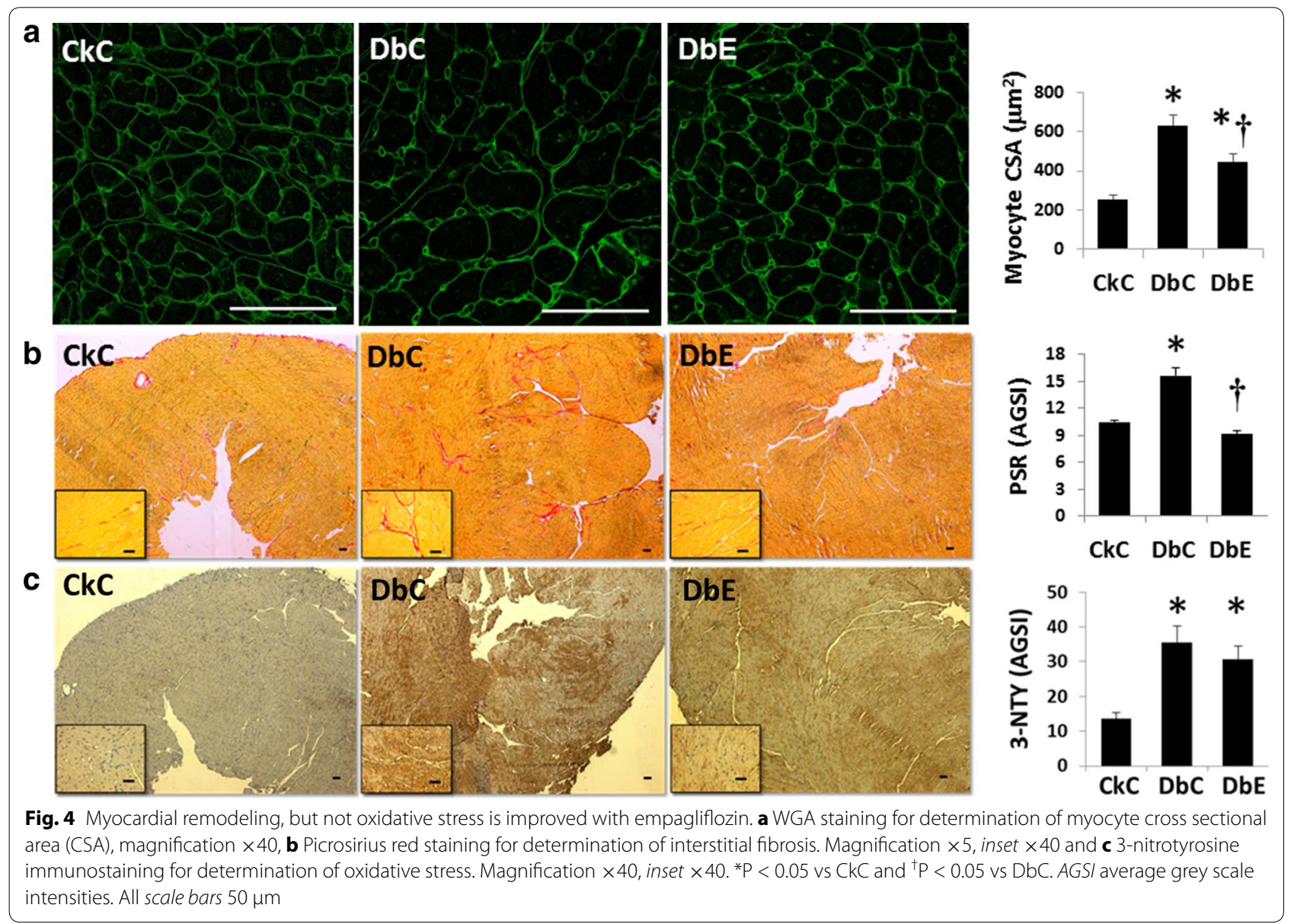

SGK1 upregulates ion channels, including $\mathrm{ENaC}$, and is likewise a potent inducer of the SGLT1, a novel cardiac glucose transporter in type 2 diabetes [40]. Myocardial ENaC protein level (Fig. 6a), assessed by immunoblotting, was significantly elevated in $\mathrm{DbC}$, compared to both $\mathrm{CkC}$ and DbE. We examined the expression of the $\alpha$-subunit of the $\mathrm{ENaC}$, as well as SGK1 in the LV using immunofluorescence. In this study, we observed $\sim 2$-fold increases in 


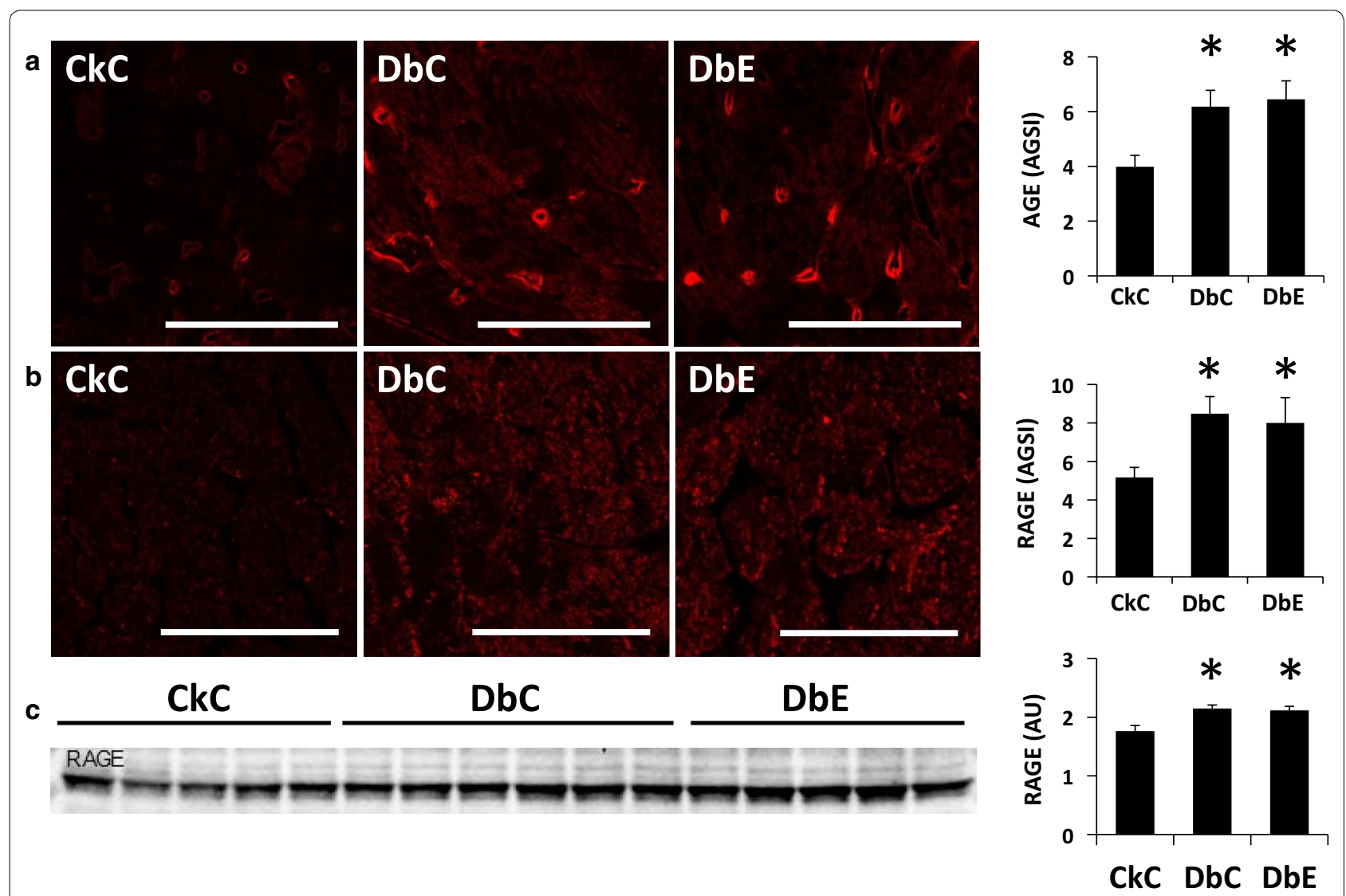

Fig. 5 Five weeks of empagliflozin treatment reduces the profibrotic protein expression levels of $\mathbf{a}, \mathbf{b} \mathrm{ENaC}$ and $\mathbf{c} \mathrm{SGK}$. AGS/ average grey scale intensities, $A \cup$ arbitrary units ${ }^{*} \mathrm{P}<0.05 \mathrm{vs} C \mathrm{CkC} ;{ }^{\dagger} \mathrm{P}<0.05 \mathrm{vs} \mathrm{DbC}$. Scale bars $50 \mu \mathrm{m}$

myocardial expression of both ENaC and SGK1 in DbC compared to $\mathrm{CkC}$, and normalization of these protein levels in DbE (Fig. 6b,c). In addition, myocardial ENaC protein level, assessed by immunoblotting, was significantly elevated in $\mathrm{DbC}$, compared to both $\mathrm{CkC}$ and $\mathrm{DbE}$. We further examined signaling pathways for hypertrophy comprising Akt and ERK activation. Although the changes in phospho Akt ser473 and Thr308 were not statistically different between the three groups, the ratio of phospho Akt to total Akt was moderately increased $(\mathrm{P}<0.055$ for ser473 and $\mathrm{P}<0.079$ for thr308) due to significant decrease in total Akt in $\mathrm{DbC}$ and $\mathrm{DbE}$ groups compared to $\mathrm{CkC}$ (Additional file 1: Figure S2). Activation of ERK1/2 is another signaling pathway implicated in cardiac hypertrophy, but this pathway was not affected either in $\mathrm{DbC}$ and $\mathrm{DbE}$ (Additional file 1: Figure S2).

\section{Myocardial ultrastructure}

Compared to $\mathrm{CkC}$, DbC exhibited a marked expansion of inter myofibrillar mitochondria (IMF Mt) resulting in a disorganized appearance of sarcomeres (Fig. 7). Additionally, mitochondria displayed attenuation of matrix electron density, loss of cristae, fusion of cristae and mitochondrial fragmentation and these ultrastructural anomalies were improved by EMPA treatment.

\section{Discussion}

Collectively, the results of this investigation support the hypothesis that treatment with the SGLT2i, EMPA, improves cardiac diastolic function in female mice in the setting of obesity and diabetes, even in the absence of a reduction in BP. The improvement in diastolic function was associated, not only with improved glycemia, but with improvements in cardiac structure, including reductions in interstitial myocardial fibrosis and associated pro-fibrotic SGK1/ENaC protein expression levels, cardiomyocyte hypertrophy and cardiomyocyte mitochondrial ultrastructure. Although EMPA is reported to reduce BP in diabetic humans [41], we did not observe lower BP in treated mice, nor did we see an improvement in BP dipping status compared to diabetic mice not receiving EMPA. Thus, functional and structural improvements in the heart of EMPA-treated mice occurred in the absence of $\mathrm{BP}$ reduction. 


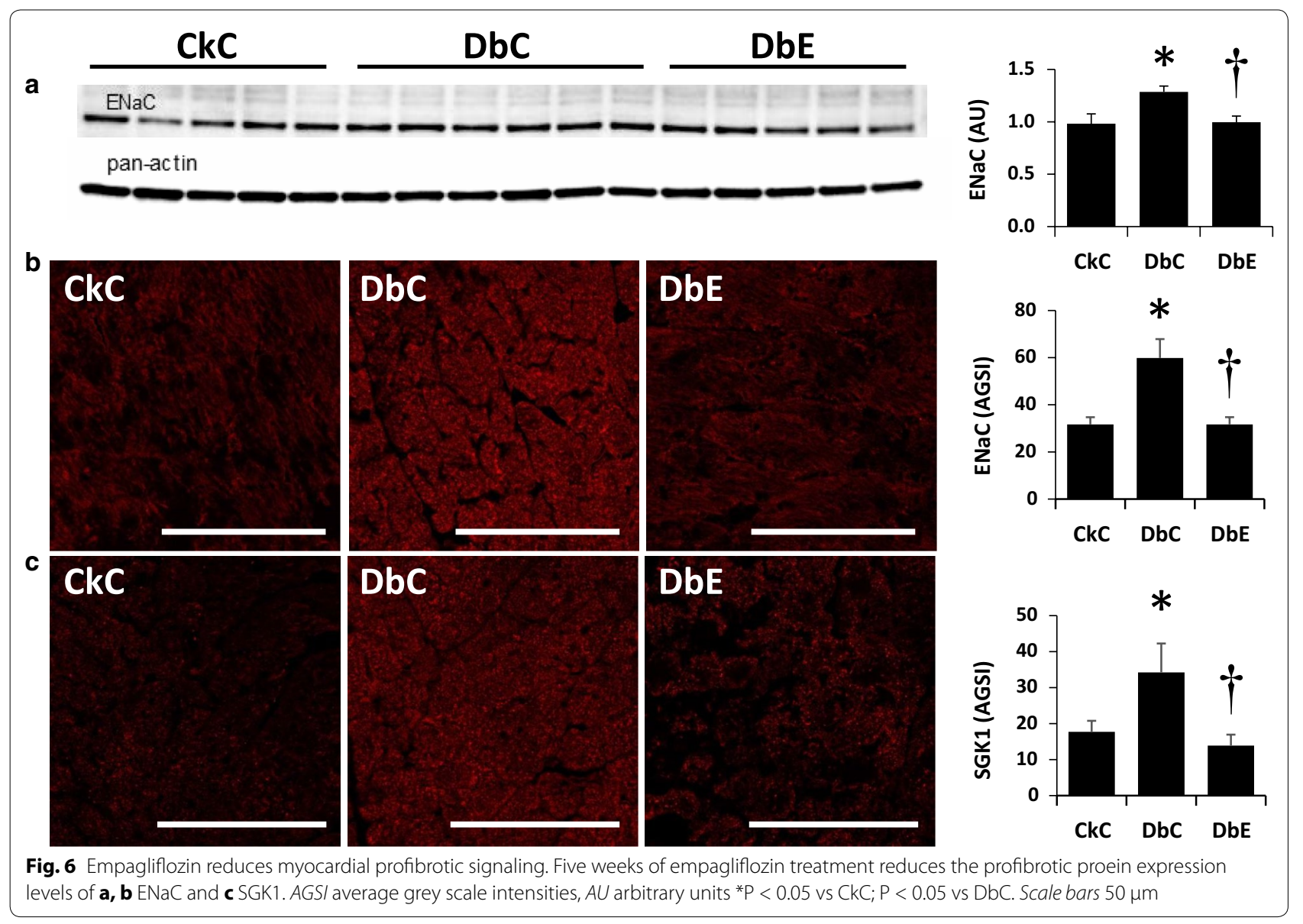

Administration of SGLT2 inhibitors is reported to improve glycemia and promote weight loss and body fat mass reduction in humans and rodents with diabetes, in part, due to caloric loss associated with increased urinary glucose excretion and a metabolic shift from carbohydrate to fatty acid oxidation [42, 43]. In this regard, a 4 week course of EMPA led to a slight reduction in triglycerides in patients with type 2 diabetes [44]. By the end of this study, we observed that $\mathrm{DbC}$ mice exhibited moderate glycosuria indicated by the 54 -fold increase in urinary glucose excretion compared to $\mathrm{CkC}$. Importantly, at the end of the study period, EMPA-treated $\mathrm{db} /$ $\mathrm{db}$ mice $\left(10 \mathrm{mg} \mathrm{kg}^{-1} \mathrm{day}^{-1}\right)$ exhibited twice the urine glucose excretion of untreated $\mathrm{db} / \mathrm{db}$ mice, thus validating long-term SGLT2 inhibition. Pharmacologic inhibition of SGLT2 has been reported to induce increases in plasma insulin concentration in $\mathrm{db} / \mathrm{db}$ mice [45] and Zucker diabetic fatty rats [46] in association with preservation of $\beta$-cell insulin secretion and consequent improved glycemia. Consistent with those previous animal studies, we observed increased plasma insulin concentration. Our results demonstrate that the low dose of EMPA used in this study blunted the progression of hyperglycemia by inducing glycosuria. Improved glycemia is associated with preservation of $\beta$-cell function $[47,48]$. Thus, the higher concentration of plasma insulin we observed with EMPA administration reflects therapeutic preservation of $\beta$-cell function and a slower decline in plasma insulin concentration. We did not observe differences in body weight or composition (lean or fat mass) or plasma or liver triglycerides between $\mathrm{DbC}$ and $\mathrm{DbE}$. Similarly, treatment of female $\mathrm{db} / \mathrm{db}$ mice for 8 weeks of EMPA at the same dose as that used herein in our study had no effect on body weight [13].

In this study we have explored the mechanisms underlying diastolic dysfunction in female $\mathrm{db} / \mathrm{db}$ mice, including myocardial fibrosis, hypertrophy and calcium handling. A major determinant of impairment of the passive properties of diastolic relaxation is cardiac fibrosis. In the setting of obesity and diabetes, an increase in myocardial interstitial fibrosis can occur in response to increased pressure or volume loading conditions and this is thought to impair normal rapid ventricular relaxation. Female diabetic $\mathrm{db} / \mathrm{db}$ mice exhibit increased cardiac interstitial fibrosis as early as 8 weeks of age [49] and we observed increased fibrosis in 16 week old females 

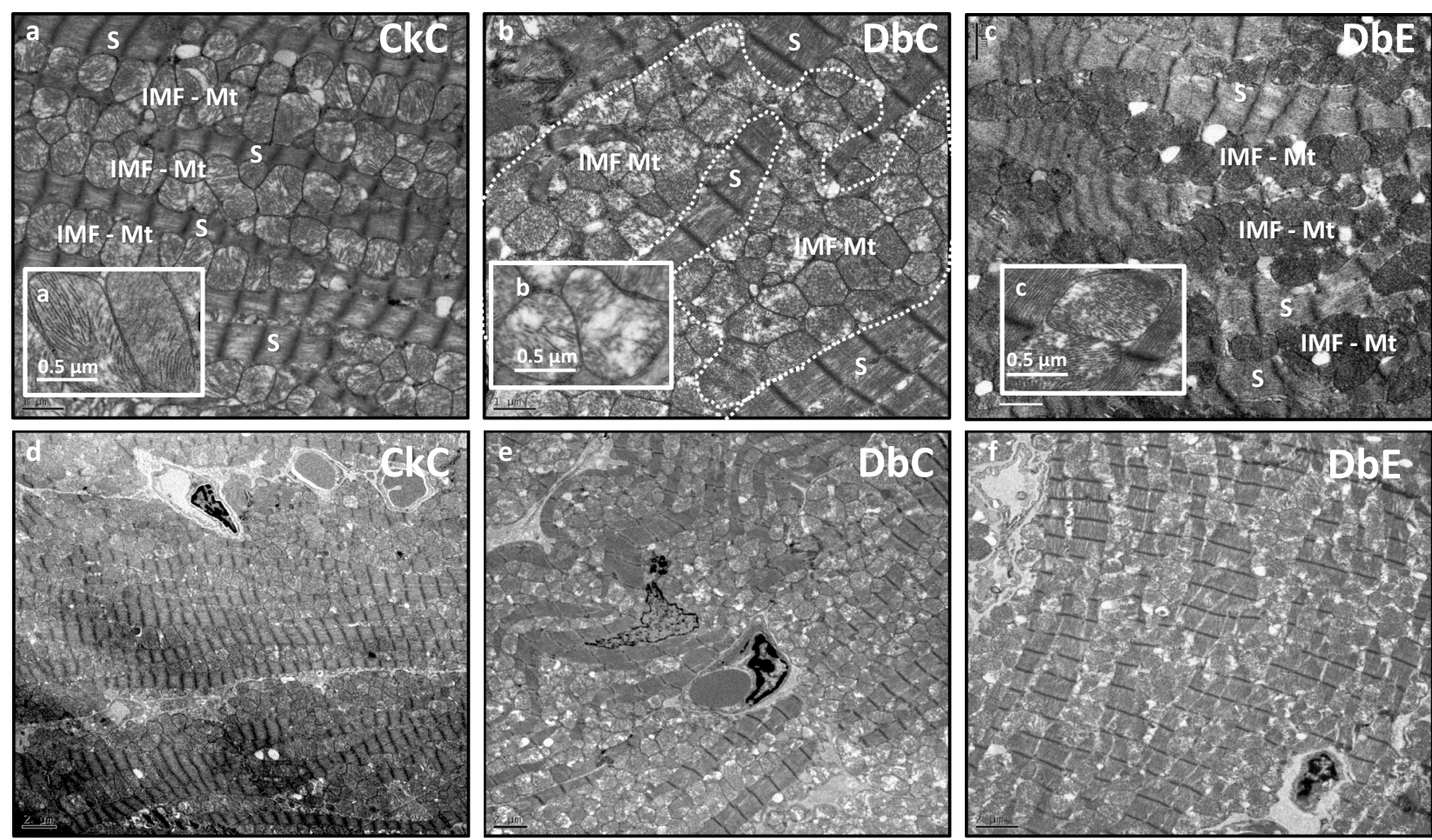

Fig. 7 Mitochondrial expansion and sarcomere disorganization in $\mathrm{DbC}$ is improved by empagliflozin treatment. a Illustrates the normal appearance of the inter myofibrillar (IMF) mitochondria (Mt) in the myocardium of CkC. Note the orderly row of sarcomeres (S) alternating with a row of IMFMt. Inset a shows normal cristae structure. b Depicts the marked IMF-Mt expansion with attenuation of the Mt matrix electron density, loss of Mt cristae (inset b), fusion of Mt cristae and Mt fragmentation in the diabetic DbC models. Also note the disorganized appearance of the sarcomeres. c Demonstrates that empagliflozin protects the cardiomyocyte from IMF-Mt expansion, decreased IMF-Mt matrix electron density, IMF-Mt cristae fragmentation (inset $\mathbf{c}$ ), fusion of cristae and loss and sarcomere disorganization. Magnification $\times 2000$; bar $1 \mu \mathrm{m}$ in $\mathbf{a}-\mathbf{c}$. Insets $\mathbf{a}-\mathbf{c}$ depict Mt cristae structure. Magnification $\times 4000$; bar $0.5 \mu \mathrm{m}$. d-f represent CKC, DbC and DbE, respectively, at lower magnifications ×800; bar $2 \mu \mathrm{m}$

(Fig. 4b). Although such a pathological remodeling response reduces LV wall stress and may confer shortterm benefits, stiffening of the myocardium can lead to reduced myocardial wall velocity during early diastole and more reliance on atrial contraction to complete filling of the LV in late diastole. Impairment in ventricular wall relaxation can be evaluated during routine echocardiography using Tissue Doppler Imaging (TDI) which allows for determination of the peak velocities of the myocardial wall during early $\left(\mathrm{E}^{\prime}\right)$ and late diastole $\left(\mathrm{A}^{\prime}\right)$. Indeed, our TDI examination revealed a reduction in the $\mathrm{E}^{\prime} / \mathrm{A}^{\prime}$ ratio in $\mathrm{DbC}$ mice before treatment began and at the end of the study suggesting chronic impaired LV wall relaxation early in diastole and enhanced late filling. Although at baseline this impairment existed in the DbE group by the end of treatment period this impairment was resolved. Perhaps most importantly, were the differences in LV filling pressure or the $\mathrm{E}$ to $\mathrm{E}^{\prime}$ ratio, among groups of mice. Unlike some diastolic parameters, such as the $\mathrm{E} / \mathrm{A}$ ratio, $\mathrm{E} / \mathrm{E}^{\prime}$ is a load-independent parameter. $\mathrm{DbC}$ exhibited increased LV filling pressure at baseline, as well as at the end of the study period, whereas, DbE mice had elevated LV filling pressure at baseline and this impairment was normalized by the end of the study. The decrease in LV filling pressure and reduction in interstitial fibrosis are consistent with an improvement in diastolic function with EMPA treatment. Our findings of impairments in TDI derived diastolic function parameters are also consistent with a recent preliminary analysis from the EMPA-REG OUTCOME trial [50]. In that study baseline echocardiography was performed on diabetes patients followed by treatment with $10 \mathrm{mg}$ day $^{-1}$ EMPA for 3 months and follow up echocardiography. EMPA resulted in an increase in $\mathrm{E}^{\prime}$ and a decrease in the LV mass index. These interesting findings suggesting that EMPA improves diastolic function will likely be explored more extensively in ongoing clinical trials.

Like cardiac fibrosis, left ventricular hypertrophy, a frequent correlate of diastolic dysfunction [51], occurs in response to increased pressure or volume loading conditions common in the setting of obesity and diabetes. We observed that standard hypertrophic parameters, 
including LV mass, LV mass adjusted for tibia length and cardiomyocyte cross sectional area, were increased or tended to be increased in both $\mathrm{DbC}$ and $\mathrm{DbE}$ compared to $\mathrm{CkC}$, and these results are consistent with a hypertrophic phenotype. Moreover, others have reported increased LV mass and wall thickness in female diabetic $\mathrm{db} / \mathrm{db}$ mice of similar age and that remodeling was associated with diastolic dysfunction [20]. In this study, relative wall thickness (RWT) did not differ among the three groups of mice. Prior to the start of treatment, anterior (LVAWTd) and posterior wall (LVPWTd) thicknesses at end diastole were moderately increased in DbC compared to $\mathrm{CkC}(\mathrm{P}<0.5)$. Wall thickness were not different between $\mathrm{DbC}$ and $\mathrm{DbE}$ and they tended to be increased in $\mathrm{DbE}$ compared to $\mathrm{CkC}(\mathrm{P}>0.05)$. Moreover, there were no differences in RWT between the groups at the end of the study. Therefore, the increase in LV mass, in concert with no change in RWT, suggests that the LV of $\mathrm{DbC}$ exhibited eccentric, rather than concentric, hypertrophy. We speculate that cardiomyocytes may be lengthening in response to volume overload associated with profound obesity, as evidenced by the increase in $\mathrm{CO}$ in $\mathrm{DbC}$. Nonetheless, DbC cardiomyocytes were more hypertrophied than those of $\mathrm{DbE}$ and $\mathrm{CkC}$ and this may be the result of stress on the LV wall caused by an increase in LV filling pressure. DbE showed lesser cardiomyocyte hypertrophy likely in response to a reduction in LV filling pressure and the decrease in cardiomyocyte hypertrophy was only a partial effect compared to the normalizing effect of EMPA on interstitial fibrosis. This suggests cardiac fibrosis contributes mainly to diastolic dysfunction.

We explored several pathways that contribute to cardiac remodeling and diastolic dysfunction, some of which have not been examined in previous studies. Emerging evidence supports a role for SGK1 and $\mathrm{ENaC}$ in promoting fibrosis and adverse hypertrophy in human and murine heart disease [7, 8]. SGK1 is highly expressed in human and murine hearts and is upregulated in pathophysiological settings, including obesity, heart disease and diabetes [40]. SGK1 regulates the expression of a number of ion channels, including $\mathrm{ENaC}[7,9]$ which is upregulated in tissues in the setting of obesity and diabetes [52]. Indeed, SGK1 is rapidly activated and induces adverse ventricular remodeling, including, fibrosis, an increase in cardiomyocyte cell size and LV hypertrophy in a murine model of transthoracic aortic constriction [7, 8]. On the other hand, SGK1 may protect cardiomyocytes from apoptosis [8]. Little is known about the role of SGK1 and ENaC in the diabetic $\mathrm{db} / \mathrm{db}$ heart or the impact of EMPA on myocardial ENaC and SGK1 expression/activation. To our knowledge, this is the first study to examine the expression of SGK1 and the $\alpha$-subunit of the epithelial sodium channel, $\mathrm{ENaC}$, in the parenchyma and vasculature of the LV. In this study, we observed increases in myocardial expression of SGK1 and $\mathrm{ENaC}$ and normalization of these protein levels by EMPA. These results suggest that the improvement in cardiac function may be modulated, in part, through improvement in SGK1/ENaC activity in the heart. The changes in expression of these proteins may be due to significant improvement in hyperglycemia since high glucose has been shown to increase the expression of SGK1 and $\mathrm{ENaC}$ in distal renal tubular cells in vitro [53]. However, the effects of high glucose on SGK1 and $\mathrm{ENaC}$ in cardiomyocytes or coronary endothelial cells of $\mathrm{db} / \mathrm{db}$ mice has not been examined. We also examined the potential contribution of the pro-hypertrophic signaling pathways, Akt and ERK (Additional file 1: Figure S2). Although compared to $\mathrm{CkC}$, Akt tended to be activated in both $\mathrm{DbC}$ and $\mathrm{DbE}$, there was no difference in the activation state between $\mathrm{DbC}$ and $\mathrm{DbE}$. The activation state of ERK did not differ among groups of mice. Thus, the modest improvement in hypertrophy in DbE is not likely mediated by effects of EMPA on Akt or ERK. The absence of evidence for contributions from Akt and ERK to cardiac remodeling in female $\mathrm{db} / \mathrm{db}$ mice examined in this study highlight the potential contributions of SGK1 and eNAC to cardiac fibrosis and hypertrophy.

In this study, changes in sarco/endoplasmic reticulum $\mathrm{Ca}^{2+}$-ATPase (SERCA), SERCA to phospholamban (PLB) ratio and phosphorylation of PLB may potentially affect diastolic function [54]. Although others have reported altered gene expression of SERCA2A and PLB in 18 week old female $\mathrm{db} / \mathrm{db}$ mice, we observed no differences among groups in protein expression (not shown) and thus cannot ascribe the differences in diastolic function observed among these proteins. Thus, we conclude these pathways do not explain the improvements in cardiac function observed. On the other hand, we did observe improved cardiomyocyte mitochondrial ultrastructure and sarcomere organization that may, in part, contribute to improved diastolic function as we have observed in this and other rodent models of cardiac dysfunction and obesity [29, 31, 32, 55].

Signaling through RAGE has been implicated in numerous disease conditions, including diabetes and heart disease. RAGE can bind multiple ligand types, including, but not limited to a heterogenous group of advanced glycation end products (AGEs). AGEs accumulate as a consequence of long-term hyperglycemia and contribute to the pathogenesis of diabetic cardiomyopathy [56]. AGE accumulation can lead to generation of reactive oxygen species (ROS) and upregulation of RAGE. Moreover, AGEs have been shown to induce the expression of $\mathrm{ENaC}$ via activation of SGK1 [57]. Recent evidence in mice suggests there is RAGE upregulation in cardiomyocytes that contributes to cardiomyopathy 
[58]. Herein, we show that myocardial AGE expression is increased in $\mathrm{DbC}$ and $\mathrm{DbE}$, compared to $\mathrm{CkC}$, and observe that it is widely distributed throughout the LV wall, including in the vasculature. This occurred in concert with increased RAGE expression. In the $\mathrm{DbC}$, the increases in both AGE and RAGE were associated with an increase in oxidative stress. Nonetheless, despite the modest improvement in HbA1c in DbE, EMPA did not reduce AGE accumulation in the heart. In this regard, a recent study utilizing a rodent model of type 1 (streptozotocin model) diabetes, reported that a low dose of EMPA (10 mg kg ${ }^{-1}$ day $\left.^{-1}\right)$, the same dose used in this study, was not associated with suppression of AGE, RAGE or ROS formation in aortic tissue or serum methylglyoxal, an AGE precursor, although treatment did improve aortic remodeling and reactivity to acetylcholine [16]. In that study, a threefold higher dose of EMPA did reduce AGE and RAGE expression, as well as ROS formation in the aortic wall. It should be noted that the glycation process in vivo results in formation of early glycation products, such as HbA1c and glycated albumin, whereas advanced glycation products require longer times to accumulate relative to early glycation products. In this regard, a previous study reported that advanced glycated $\mathrm{Hb}$ (Hb-AGE) was significantly increased with high level of HbA1c in diabetic patients, but Hb-AGE did not correlate with diabetes duration and correlated poorly in a well-controlled sub-group [59].

Evidence from a recent clinical trial (EMPA-REG $\mathrm{BP}^{\mathrm{TM}}$ ) examining the effects of a 12 week course of EMPA on male and female patients with type 2 diabetes and hypertension demonstrates improvements in both sexes in SBP and DBP ( 3.9 and $1.5 \mathrm{mmHg}$, respectively compared to placebo), as well as indirect markers of arterial stiffness and vascular resistance $[41,60]$. In the untreated $\mathrm{db} / \mathrm{db}$ mice examined here $(\mathrm{DbC})$, we observed increased SBP and DBP, as well as impaired BP dipping, all of which were unaffected by EMPA. It is possible that the 5 week duration of our study was too brief to induce a detectable decrease in BP.

Coinciding with the preparation of this manuscript there was a more recent report from the EMPA-REG outcome trial demonstrating improvement in Tissue Doppler derived diastolic function in diabetes patients administered EMPA [50]. That EMPA resulted in similar improvement in myocardial wall relaxation in both diabetes patients and in diabetic $\mathrm{db} / \mathrm{db}$ mice suggests that the present $\mathrm{db} / \mathrm{db}$ model has potential clinical translational relevance.

The absence of data on the effects of EMPA on myocardial metabolism and insulin sensitivity is a limitation of this study. In this regard, a recent study reported increases in glucose disposal rate and liver, kidney and heart tissue glucose uptake, by euglycemic-hyperinsulinemic clamp, in female $\mathrm{db} / \mathrm{db}$ mice treated with EMPA for 8 weeks at the same dose used in this study [13]. Thus it is possible that the improvement in diastolic dysfunction observed in this study could be due, in part, to increased myocardial glucose uptake and improvement in myocardial insulin sensitivity. Further study is needed to determine whether improvement in myocardial insulin sensitivity contributes to improved diastolic function in $\mathrm{db} / \mathrm{db}$ mice treated with EMPA.

In conclusion, data presented herein support a newly described pleiotropic protective affect of EMPA on diastolic function and cardiac structure in the diabetic $\mathrm{db} /$ $\mathrm{db}$ mouse with established impaired diastolic relaxation, albuminuria and elevated BP. Specifically, we observed improvement in diastolic function, myocardial fibrosis, cardiomyocyte hypertrophy and ultrastructure of inter myofibrillar mitochondria that were associated with a significant improvement in glycemia, as well as improvement in myocardial expression of SGK1 and ENaC. Despite the improvement in glycemic control, HbA1c and fasting glucose were still elevated above normoglycemia values. Moreover, we did not see any marked improvements in body composition, lipid (plasma or liver triglycerides) or BP control or BP dipping, or reductions in myocardial accumulation of AGE/ RAGE and protein nitrosylation with 5 weeks of EMPA treatment. It was recently highlighted that the unexplained aspects of the EMPA-REG OUTCOME results are that the cardiovascular and kidney benefits of EMPA occurred without dramatic improvements in glycemic, lipid, or BP control [61]. Therefore, it is possible that the pleiotropic effects of EMPA relate to factors other than improvements in glycemia and lipidemia. In this regard, the effect of EMPA on metabolic remodeling in tissues is emerging [61, 62]. Additional studies are needed to further elucidate the potential role for myocardial SGK1 and $\mathrm{ENaC}$ as mediators of the efficacy of EMPA. The findings of this investigation in a preclinical model suggest a potential clinical utility for EMPA in the treatment of diastolic dysfunction given the high incidence of diastolic dysfunction and the cardiovascular risks associated with this abnormality in the diabetic population and in women in particular.

\section{Additional file}

Additional file 1. Additional figures.

Authors' contributions

VGD, AA, EM, AWC and JRS made substantial contributions to conception and study design. JH, VGD AWC and AA were involved in drafting and revising the manuscript, including statistical analysis and data interpretation, and graphics. $J H, A A, G J, M R H, M G, B B, S R, J R S, A W C$ and VGD contributed to the acquisition 
and interpretation of data and associated intellectual content. All authors read and approved the final manuscript.

\section{Author details}

1 Department of Medicine, Division of Endocrinology, Diabetes and Cardiovascular Center, University of Missouri, School of Medicine, Columbia, USA. ${ }^{2}$ Division of Nephrology, University of Missouri, School of Medicine, Columbia, USA. ${ }^{3}$ Department of Medical Pharmacology and Physiology, University of Missouri, School of Medicine, Columbia, USA. ${ }^{4}$ Research Service, Harry S. Truman Memorial Veterans Hospital, Columbia, MO, USA. ${ }^{5}$ The Dalton Cardiovascular Research Center, Columbia, MO, USA. ${ }^{6}$ Departments of Medicine-Gastroenterology and Hepatology and Nutrition and Exercise Physiology, University of Missouri, Columbia, MO, USA. ${ }^{7}$ Department of Cardiometabolic Diseases Research, Boehringer-Ingelheim, Biberach, Germany.

\section{Acknowledgements}

The authors thank Brenda Hunter for editorial assistance and Dongqing Chen, Alex Meuth and Grace Meers for technical assistance (University of Missouri). We also appreciate the assistance provided by the Small Animal Ultrasound Imaging Center (SAUIC), located at the Harry S Truman VA Hospital, Columbia, MO, as well as the VA Research and Development Office and the Missouri Foundation for Veteran's Medical Research.

\section{Competing interests}

VGD received unrestricted funding for an investigator initiated proposal from Boerhinger Ingelheim to perform this study. EM is an employee of Boerhinger Ingelheim

\section{Availability of data and materials}

Please contact author for data requests.

\section{Funding}

This work was supported by an unrestricted research grant from Boehringer Ingelheim Pharma (VGD), as well as support from the National Institutes of Health (R01-HL073101 RO1-HL107910), Veteran Affairs (VA) Merit (0018) to JRS and VA-CDA2 BX001299 (SRR) and Boehringer Ingelheim Pharma (EM). This work was supported by resources and facilities at the Harry S. Truman Memorial Veterans' Hospital in Columbia, MO.

Received: 9 September 2016 Accepted: 25 December 2016

Published online: 13 January 2017

\section{References}

1. Peterson LR, Herrero P, Schechtman KB, Racette SB, Waggoner AD, Kisrieva-Ware Z, Dence C, Klein S, Marsala J, Meyer T, et al. Effect of obesity and insulin resistance on myocardial substrate metabolism and efficiency in young women. Circulation. 2004;109(18):2191-6.

2. Peterson LR, Waggoner AD, Schechtman KB, Meyer T, Gropler RJ, Barzilai B, Davila-Roman VG. Alterations in left ventricular structure and function in young healthy obese women: assessment by echocardiography and tissue Doppler imaging. J Am Coll Cardiol. 2004;43(8):1399-404.

3. Howard BV, Cowan LD, Go O, Welty TK, Robbins DC, Lee ET. Adverse effects of diabetes on multiple cardiovascular disease risk factors in women. The Strong Heart Study. Diabetes Care. 1998;21 (8):1258-65.

4. Zile MR, Baicu CF, Gaasch WH. Diastolic heart failure-abnormalities in active relaxation and passive stiffness of the left ventricle. N Engl J Med. 2004;350(19):1953-9.

5. Schilling JD, Mann DL. Diabetic cardiomyopathy: bench to bedside. Heart Fail Clin. 2012;8(4):619-31

6. Rutter MK, Parise H, Benjamin EJ, Levy D, Larson MG, Meigs JB, Nesto RW, Wilson PW, Vasan RS. Impact of glucose intolerance and insulin resistance on cardiac structure and function: sex-related differences in the Framingham Heart Study. Circulation. 2003;107(3):448-54.

7. Das S, Aiba T, Rosenberg M, Hessler K, Xiao C, Quintero PA, Ottaviano FG Knight AC, Graham EL, Bostrom P, et al. Pathological role of serum- and glucocorticoid-regulated kinase 1 in adverse ventricular remodeling. Circulation. 2012;126(18):2208-19.
8. Aoyama T, Matsui T, Novikov M, Park J, Hemmings B, Rosenzweig A. Serum and glucocorticoid-responsive kinase-1 regulates cardiomyocyte survival and hypertrophic response. Circulation. 2005;111(13):1652-9.

9. Lang F, Shumilina E. Regulation of ion channels by the serum- and glucocorticoid-inducible kinase SGK1. FASEB J. 2013;27(1):3-12.

10. Willemsen S, Hartog JW, Heiner-Fokkema MR, van Veldhuisen DJ, Voors AA. Advanced glycation end-products, a pathophysiological pathway in the cardiorenal syndrome. Heart Fail Rev. 2012;17(2):221-8.

11. Lang F, Artunc F, Vallon V. The physiological impact of the serum and glucocorticoid-inducible kinase SGK1. Curr Opin Nephrol Hypertens. 2009;18(5):439-48.

12. Jia G, Habibi J, Aroor AR, Martinez-Lemus LA, DeMarco VG, Ramirez-Perez Fl, Sun Z, Hayden MR, Meininger GA, Barrett Mueller KV, et al. Endothelial mineralocorticoid receptor mediates diet induced aortic stiffness in females. Circ Res. 2016;118(6):935-43.

13. Kern M, Kloting N, Mark M, Mayoux E, Klein T, Bluher M. The SGLT2 inhibitor empagliflozin improves insulin sensitivity in $\mathrm{db} / \mathrm{db}$ mice both as monotherapy and in combination with linagliptin. Metabolism. 2016;65(2):114-23.

14. Merovci A, Solis-Herrera C, Daniele G, Eldor R, Fiorentino TV, Tripathy D, Xiong J, Perez Z, Norton L, Abdul-Ghani MA, et al. Dapagliflozin improves muscle insulin sensitivity but enhances endogenous glucose production. J Clin Investig. 2014;124(2):509-14.

15. Zinman B, Wanner C, Lachin JM, Fitchett D, Bluhmki E, Hantel S, Mattheus M, Devins T, Johansen OE, Woerle HJ, et al. Empagliflozin, cardiovascular outcomes, and mortality in type 2 diabetes. N Engl J Med. 2015;373(22):2117-28.

16. Oelze M, Kroller-Schon S, Welschof $P$, Jansen T, Hausding M, Mikhed $Y$, Stamm P, Mader M, Zinssius E, Agdauletova S, et al. The sodium-glucose co-transporter 2 inhibitor empagliflozin improves diabetes-induced vascular dysfunction in the streptozotocin diabetes rat model by interfering with oxidative stress and glucotoxicity. PLOS ONE. 2014:9(11):e112394.

17. Peterson LR, Soto PF, Herrero P, Mohammed BS, Avidan MS, Schechtman $\mathrm{KB}$, Dence C, Gropler RJ. Impact of gender on the myocardial metabolic response to obesity. JACC Cardiovasc Imaging. 2008;1 (4):424-33.

18. Peterson LR, Saeed IM, McGill JB, Herrero P, Schechtman KB, Gunawardena R, Recklein CL, Coggan AR, Demoss AJ, Dence CS, et al. Sex and type 2 diabetes: obesity-independent effects on left ventricular substrate metabolism and relaxation in humans. Obesity. 2012;20(4):802-10.

19. Ren J, Ceylan-Isik AF. Diabetic cardiomyopathy: do women differ from men? Endocrine. 2004;25(2):73-83.

20. Yue P, Arai T, Terashima M, Sheikh AY, Cao F, Charo D, Hoyt G, Robbins RC, Ashley EA, Wu J, et al. Magnetic resonance imaging of progressive cardiomyopathic changes in the $\mathrm{db} / \mathrm{db}$ mouse. Am J Physiol Heart Circ Physiol. 2007:292(5):H2106-18.

21. Bowden MA, Tesch GH, Julius TL, Rosli S, Love JE, Ritchie RH. Earlier onset of diabesity-induced adverse cardiac remodeling in female compared to male mice. Obesity. 2015;23(6):1166-77.

22. Huynh K, Kiriazis H, Du XJ, Love JE, Jandeleit-Dahm KA, Forbes JM, McMullen JR, Ritchie RH. Coenzyme Q(10) attenuates diastolic dysfunction, cardiomyocyte hypertrophy and cardiac fibrosis in the $\mathrm{db} / \mathrm{db}$ mouse model of type 2 diabetes. Diabetologia. 2012;55(5):1544-53.

23. Hummel KP, Dickie MM, Coleman DL. Diabetes, a new mutation in the mouse. Science. 1966;153(3740):1127-8.

24. Coleman DL. Lessons from studies with genetic forms of diabetes in the mouse. Metabolism. 1983;32(7 Suppl 1):162-4.

25. da Costa Goncalves AC, Tank J, Diedrich A, Hilzendeger A, Plehm R, Bader M, Luft FC, Jordan J, Gross V. Diabetic hypertensive leptin receptordeficient $\mathrm{db} / \mathrm{db}$ mice develop cardioregulatory autonomic dysfunction. Hypertension. 2008:53:387-92.

26. Su W, Guo Z, Randall DC, Cassis L, Brown DR, Gong MC. Hypertension and disrupted blood pressure circadian rhythm in type 2 diabetic $\mathrm{db} / \mathrm{db}$ mice. Am J Physiol Heart Circ Physiol. 2008;295(4):H1634-41.

27. Zhang H, Morgan B, Potter BJ, Ma L, Dellsperger KC, Ungvari ZI, Zhang C. Resveratrol improves left ventricular diastolic relaxation in type 2 diabetes by inhibiting oxidative/nitrative stress. Am J Physiol Heart Circ Physiol. 2010;299:985-94.

28. Grempler R, Thomas L, Eckhardt M, Himmelsbach F, Sauer A, Sharp DE, Bakker RA, Mark M, Klein T, Eickelmann P. Empagliflozin, a novel selective sodium glucose cotransporter-2 (SGLT-2) inhibitor: characterisation 
and comparison with other SGLT-2 inhibitors. Diabetes Obes Metab. 2012;14(1):83-90.

29. Zhou X, Ma L, Habibi J, Whaley-Connel AT, Hayden MR, Tilmon RD, Brown AN, DeMarco VG, Sowers JR. Nebivolol improves diastolic dysfunction and myocardial tissue remodeling through reductions in oxidative stress in the Zucker obese rat. Hypertension. 2010;55(4):880-8.

30. Rector RS, Thyfault JP, Morris RT, Laye MJ, Borengasser SJ, Booth FW, Ibdah $J A$. Daily exercise increases hepatic fatty acid oxidation and prevents steatosis in Otsuka Long-Evans Tokushima Fatty rats. Am J Physiol Gastrointest Liver Physiol. 2008;294(3):G619-26.

31. Aroor AR, Sowers JR, Bender SB, Nistala R, Garro M, Mugerfeld I, Hayden MR, Johnson MS, Salam M, Whaley-Connell A, et al. Dipeptidylpeptidase inhibition is associated with improvement in blood pressure and diastolic function in insulin resistant male Zucker obese rats. Endocrinology. 2013;154(7):2501-13.

32. Demarco VG, Ford DA, Henriksen EJ, Aroor AR, Johnson MS, Habibi J, Ma L, Yang M, Albert CJ, Lally JW, et al. Obesity-related alterations in cardiac lipid profile and nondipping blood pressure pattern during transition to diastolic dysfunction in male db/db mice. Endocrinology. 2013;154(1):159-71.

33. Manrique C, Demarco VG, Aroor AR, Mugerfeld I, Garro M, Habibi J, Hayden MR, Sowers JR. Obesity and insulin resistance induce early development of diastolic dysfunction in young female mice fed a western diet. Endocrinology. 2013;154(10):3632-42.

34. Jia G, Habibi J, DeMarco VG, Martinez-Lemus LA, Ma L, Whaley-Connell AT, Aroor AR, Domeier TL, Zhu Y, Meininger GA, et al. Endothelial mineralocorticoid receptor deletion prevents diet-induced cardiac diastolic dysfunction in females. Hypertension. 2015;66:1159-67.

35. Demarco VG, Johnson MS, Ma L, Pulakat L, Mugerfeld I, Hayden MR, Garro M, Knight WC, Britton SL, Koch LG, et al. Overweight female rats selectively bred for low aerobic capacity exhibit increased myocardial fibrosis and diastolic dysfunction. Am J Physiol Heart Circ Physiol. 2012;302:H1667-82.

36. Jia G, Habibi J, Bostick BP, Ma L, DeMarco VG, Aroor AR, Hayden MR, Whaley-Connell AT, Sowers JR. Uric acid promotes left ventricular diastolic dysfunction in mice fed a Western diet. Hypertension. 2015;65(3):531-9.

37. Park JH, Marwick TH. Use and limitations of E/e' to assess left ventricular filling pressure by echocardiography. J Cardiovasc Ultrasound. 2011;19(4):169-73.

38. de Simone G, Devereux RB, Roman MJ, Alderman MH, Laragh JH. Relation of obesity and gender to left ventricular hypertrophy in normotensive and hypertensive adults. Hypertension. 1994;23(5):600-6.

39. Hiraumi Y, Iwai-Kanai E, Baba S, Yui Y, Kamitsuji Y, Mizushima Y, Matsubara H, Watanabe M, Watanabe K, Toyokuni S, et al. Granulocyte colony-stimulating factor protects cardiac mitochondria in the early phase of cardiac injury. Am J Physiol Heart Circ Physiol. 2009;296(3):H823-32.

40. Lang F, Bohmer C, Palmada M, Seebohm G, Strutz-Seebohm N, Vallon V. (Patho)physiological significance of the serum- and glucocorticoidinducible kinase isoforms. Physiol Rev. 2006;86(4):1151-78.

41. Tikkanen I, Narko K, Zeller C, Green A, Salsali A, Broedl UC, Woerle HJ. Empagliflozin reduces blood pressure in patients with type 2 diabetes and hypertension. Diabetes Care. 2015;38(3):420-8.

42. Yokono M, Takasu T, Hayashizaki Y, Mitsuoka K, Kihara R, Muramatsu Y, Miyoshi S, Tahara A, Kurosaki E, Li Q, et al. SGLT2 selective inhibitor ipragliflozin reduces body fat mass by increasing fatty acid oxidation in high-fat diet-induced obese rats. Eur J Pharmacol. 2014;727:66-74.

43. Ferrannini E, Ramos SJ, Salsali A, Tang W, List JF. Dapagliflozin monotherapy in type 2 diabetic patients with inadequate glycemic control by diet and exercise: a randomized, double-blind, placebo-controlled, phase 3 trial. Diabetes Care. 2010;33(10):2217-24.

44. Nishimura R, Tanaka Y, Koiwai K, Inoue K, Hach T, Salsali A, Lund SS, Broedl UC. Effect of empagliflozin monotherapy on postprandial glucose and 24-hour glucose variability in Japanese patients with type 2 diabetes mellitus: a randomized, double-blind, placebo-controlled, 4-week study. Cardiovasc Diabetol. 2015;14:11.
45. Lin B, Koibuchi N, Hasegawa Y, Sueta D, Toyama K, Uekawa K, Ma M, Nakagawa T, Kusaka H, Kim-Mitsuyama S. Glycemic control with empagliflozin, a novel selective SGLT2 inhibitor, ameliorates cardiovascular injury and cognitive dysfunction in obese and type 2 diabetic mice. Cardiovasc Diabetol. 2014;13(1):148.

46. Kuriyama C, Xu JZ, Lee SP, Qi J, Kimata H, Kakimoto T, Nakayama K, Watanabe Y, Taniuchi N, Hikida K, et al. Analysis of the effect of canagliflozin on renal glucose reabsorption and progression of hyperglycemia in zucker diabetic fatty rats. J Pharmacol Exp Ther. 2014;351(2):423-31.

47. Hansen HH, Jelsing J, Hansen CF, Hansen G, Vrang N, Mark M, Klein T, Mayoux E. The sodium glucose cotransporter type 2 inhibitor empagliflozin preserves beta-cell mass and restores glucose homeostasis in the male zucker diabetic fatty rat. J Pharmacol Exp Ther. 2014;350(3):657-64.

48. Jurczak MJ, Lee HY, Birkenfeld AL, Jornayvaz FR, Frederick DW, Pongratz RL, Zhao X, Moeckel GW, Samuel VT, Whaley JM, et al. SGLT2 deletion improves glucose homeostasis and preserves pancreatic beta-cell function. Diabetes. 2011;60(3):890-8.

49. Gonzalez-Quesada C, Cavalera M, Biernacka A, Kong P, Lee DW, Saxena A, Frunza O, Dobaczewski M, Shinde A, Frangogiannis NG. Thrombospondin-1 induction in the diabetic myocardium stabilizes the cardiac matrix in addition to promoting vascular rarefaction through angiopoietin-2 upregulation. Circ Res. 2013;113(12):1331-44.

50. Verma S, Garg A, Yan AT, Gupta AK, Al-Omran M, Sabongui A, Teoh H, Mazer CD, Connelly KA. Effect of empagliflozin on left ventricular mass and diastolic function in individuals with diabetes: an important clue to the EMPA-REG OUTCOME Trial? Diabetes Care. 2016;39(12):e212-3.

51. Mandavia CH, Aroor AR, Demarco VG, Sowers JR. Molecular and metabolic mechanisms of cardiac dysfunction in diabetes. Life Sci. 2012;92(11):601-8.

52. Bubien JK. Epithelial $\mathrm{Na}+$ channel (ENaC), hormones, and hypertension. J Biol Chem. 2010;285(31):23527-31.

53. Hills CE, Bland R, Bennett J, Ronco PM, Squires PE. High glucose upregulates ENaC and SGK1 expression in HCD-cells. Cell Physiol Biochem. 2006;18(6):337-46.

54. Periasamy M, Janssen PM. Molecular basis of diastolic dysfunction. Heart Fail Clin. 2008;4(1):13-21.

55. Bostick B, Habibi J, DeMarco VG, Jia G, Domeier TL, Lambert MD, Aroor AR, Nistala R, Bender SB, Garro M, et al. Mineralocorticoid receptor blockade prevents western diet-induced diastolic dysfunction in female mice. Am J Physiol Heart Circ Physiol. 2015;308(9):H1 126-35.

56. Bodiga VL, Eda SR, Bodiga S. Advanced glycation end products: role in pathology of diabetic cardiomyopathy. Heart Fail Rev. 2014;19(1):49-63.

57. Chang CT, Wu MS, Tian YC, Chen KH, Yu CC, Liao CH, Hung CC, Yang CW. Enhancement of epithelial sodium channel expression in renal cortical collecting ducts cells by advanced glycation end products. Nephrol Dial Transplant. 2007:22(3):722-31.

58. Nelson MB, Swensen AC, Winden DR, Bodine JS, Bikman BT, Reynolds PR. Cardiomyocyte mitochondrial respiration is reduced by receptor for advanced glycation end-product signaling in a ceramide-dependent manner. Am J Physiol Heart Circ Physiol. 2015;309(1):H63-9.

59. Turk Z, Mesic R, Benko B. Comparison of advanced glycation endproducts on haemoglobin (Hb-AGE) and haemoglobin A1c for the assessment of diabetic control. Clin Chim Acta. 1998;277(2):159-70.

60. Chilton R, Tikkanen I, Cannon CP, Crowe S, Woerle HJ, Broedl UC, Johansen OE. Effects of empagliflozin on blood pressure and markers of arterial stiffness and vascular resistance in patients with type 2 diabetes. Diabetes Obes Metab. 2015;17:1180.

61. Mudaliar S, Alloju S, Henry RR. Can a shift in fuel energetics explain the beneficial cardiorenal outcomes in the EMPA-REG OUTCOME Study? A unifying hypothesis. Diabetes Care. 2016;39(7):1115-22.

62. Ferrannini E, Mark M, Mayoux E. CV protection in the EMPA-REG OUTCOME Trial: a "Thrifty Substrate" hypothesis. Diabetes Care. 2016;39(7):1108-14. 